\title{
Cardenolide Increase in Foxglove During Stresses Corresponds to Cholesterol and Phytosterol Biosynthesis
}

\author{
Indu Raghavan ${ }^{1}$, Baradwaj G. Ravi ${ }^{1}$, Emily Carroll ${ }^{1}$, Zhen Q. Wang ${ }^{* 1}$ \\ ${ }^{1}$ Department of Biological Sciences, University at Buffalo, State University at New York, Buffalo, NY14221 \\ "Corresponding author: Zhen Q. Wang zhenw@buffalo.edu
}

Keywords: cardiac glycosides, Digitalis lanata, methyl jasmonate, 2,1,3-benzothiadiazole, salicylic acid, sterol sidechain reductase, sterol methyl oxidase

\begin{abstract}
Cardenolides are a group of steroidal metabolites found in Digitalis lanata with potent cardioactive effects on animals. In plants, cardenolides are involved in various stress responses. However, the molecular mechanism of cardenolide increase during stresses is mostly unknown. Here we show that cardenolides were increased upon methyl jasmonate (MJ), sorbitol, potassium $(\mathrm{KCl})$ chloride, and salicylic acid analog (BTH: 2,1,3-benzothiadiazole) treatments. However, the expression of three known genes for cardenolide biosynthesis did not correlate well with these increases. Specifically, the expression of progesterone-5 $\beta$-reductases (P5 $\beta \mathrm{R}$ and P5 $\beta \mathrm{R} 2$ ) did not correlate with cardenolide increase. The expression of $3 \beta-$ hydroxysteroid dehydrogenase $(3 \beta \mathrm{HSD})$ correlated with cardenolide levels only during the $\mathrm{BTH}$ treatment. Mining the $D$. lanata transcriptome identified genes involved in cholesterol and phytosterol biosynthesis: SSR1 (sterol sidechain reductase), SMO1, and SMO3 (sterol methyl oxidase). Surprisingly, the expression of all three genes correlated well with the cardenolide increase after BTH treatment. Phylogenetic analysis showed that SSR1 is likely involved in both cholesterol and phytosterol biosynthesis. In addition, SMO1 is likely specific to phytosterol biosynthesis, and $\mathrm{SMO} 3$ is specific to cholesterol biosynthesis. These results suggest that both cholesterol and phytosterol are involved in cardenolide biosynthesis. In summary, this work shows that cardenolides are important for stress responses in D. lanata and revealed a novel relationship between phytosterol and cardenolide biosynthesis.
\end{abstract}

\section{Introduction}

Cardiac glycosides are plant-based steroidal compounds immensely important to the pharmaceutical industry because of their cardiotonic properties (Gurel et al. 2017). Digoxin, one of the cardiac glycosides, is a common medicine for arrhythmia and heart failure (Organization 2013). Novel therapeutic applications of cardiac glycosides for treating cancer, viral infections, cystic fibrosis, and neurodegenerative diseases are under investigation (Prassas and Diamandis 2008), (Kreis 2017), (Mekhail et al. 2006), (Mijatovic et al. 2006), (Manna et al. 2006), (Piccioni et al. 2004) (Bertol et al. 2011), (Calderón-Montaño et al. 2014), (Schneider et al. 2016), (Wang et al. 2009), (Srivastava et al. 2004), (Haux et al. 2000). Cardiac glycosides 
are industrially produced from cultivating the woolly foxglove (Digitalis lanata) (Fonin and Ala 2003). Other plant species in the family of Apocynaceae and certain animals such as toads also produce cardiac glycosides (Agrawal et al. 2012), (Bókony et al. 2019). Cardiac glycosides are also constantly present in human serum ((Hamlyn et al. 1991), (Ludens et al. 1991), (Mathews et al. 1991)). Cardiac glycosides include two classes: cardenolides with a five-membered lactone ring and bufadienolides with a six-membered lactone ring. Cardenolides with four sugar moieties are referred to as primary cardenolides, including lanatoside $A, B, C, D$ and $E$ in $D$. lanata (Ravi et al. 2020b), (Ravi et al. 2020a). The terminal glucose in lanatosides is hydrolyzed away during the harvesting process, generating secondary cardenolides such as digoxin.

Despite the potent effects of cardiac glycosides on the heart muscles, the physiological function of cardiac glycosides in plants is less understood. Previous work has shown that various stresses such as wounding, $\mathrm{H}_{2} \mathrm{O}_{2}$, salicylic acid, sorbitol, and fungal extracts increased cardenolides in different species of Digitalis (Pérez-Bermúdez et al. 2010), (Patil et al. 2013), (Cingoz et al. 2014), (Palazón et al. 1995), (Cingoz et al. 2014), (Cingoz and Gurel 2016). However, the molecular mechanism for the observed increase is mostly unknown. Compounding the issue is the incomplete list of genes responsible for cardenolide biosynthesis. The substrate for cardenolides is proposed to be cholesterol. Nine steps of enzymatic transformation convert cholesterol to the steroidal core, digitoxigenin (Figure 1). The following steps, including glycosylation, acetylation, and oxidation, generate over 100 different cardiac glycosides (Prassas and Diamandis 2008). Only three genes for cardenolide biosynthesis have

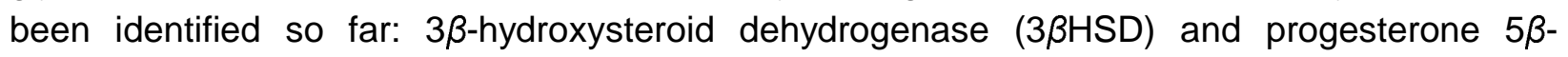
reductases (P5 $\beta R$ and P5 $\beta$ R2) (Herl et al. 2007), (Herl et al. 2006), (Pérez-Bermúdez et al. 2010). It is also unclear whether cholesterol is the bona fide substrate since its concentration in plants is low. Phytosterols, which are major sterols in plants, may also be precursors of cardenolides (Milek et al. 1997) (Valitova et al. 2016).

In Digitalis, phytosterols are about $94 \%$ of total sterols, and cholesterol is only 6\% (Milek et al. 1997). Phytosterols differ from cholesterol by the C24 methyl or ethyl substitution, therefore also known as the C24 alkylsterols. Phytosterols are formed from cycloartenol, a triterpene. After 10 to 12 steps, cycloartenol is converted to phytosterols including campesterol, stigmasterol, and sitosterol. The enzymes involved have been found in Arabidopsis. Among them, SMO1 (C4 sterol methyl oxidase) and SSR1 (sterol side chain reductase 1) were likely rate-limiting (Lange et al. 2015). How plants synthesize cholesterol is less known. In Arabidopsis, cholesterol seems to arise from the same pathway as phytosterols. However, in Solanum species, cholesterol biosynthesis is largely separated from the phytosterol pathway due to the duplications of five genes, leading to unusually high cholesterol content in these plants (Sonawane et al. 2016). How cholesterol is synthesized in Digitalis or any other species of Lamiales is unknown to the best of our knowledge.

Here, we report cardenolide levels in response to stresses using high-resolution liquid chromatography coupled with mass spectrometry (HRLC/MS) (Ravi et al. 2020b), (Ravi et al. 2020a). We have also quantified the expression of $3 \beta H S D, P 5 \beta R$, and P5 $\beta R 2$ in response to 
stresses. In addition, we have identified phytosterol and cholesterol biosynthetic genes including sterol sidechain reductase 1 (SSR1), sterol methyl oxidase 1 (SMO1), and sterol methyl oxidase 3 (SMO3). We observed that gene expressions of 3ßHSD, SSR1, SMO3, and SMO1 were highly correlated with cardenolide increase during BTH treatment, indicating that the phytosterol pathway is indeed involved in cardenolide biosynthesis.

\section{Materials and methods}

\section{Materials and chemicals}

Seeds of Digitalis lanata Ehrh were from Strictly Medicinal (Williams, Oregon, USA). The seeds were germinated and grown in the same growth conditions as described in Ravi, B.G. et al. 2020a (Ravi et al. 2020b). Methyl jasmonate (MJ) was purchased from Tokyo Chemical Industry, Tokyo, Japan. D-sorbitol was acquired from Fisher Scientific, Waltham, Massachusetts. 2,1,3-Benzothiadiazole (BTH) was from Alfa Aesar, Haverhill, Massachusetts. Yeast autolysate was from Sigma-Aldrich, Sr. Louis, Missouri, and digoxin-d3 was from Toronto Research Chemicals, Ontario, Canada. MJ was dissolved in 1\% ethanol, BTH was dissolved in $10 \%$ ethanol, and digoxin-d3 was dissolved in 95\% methanol. D-sorbitol, $\mathrm{KCl}$, and yeast autolysate were dissolved in double-distilled water. The Invitrogen turbo DNA-free kit and TRIzol reagent were purchased from Fisher Scientific, Waltham, Massachusetts. The iScript ${ }^{\mathrm{TM}} \mathrm{cDNA}^{\mathrm{T}}$ synthesis kit and iTaq universal SYBR green PCR master mix were obtained from Bio-Rad Laboratories, Hercules, California.

\section{Stress treatments for $D$. lanata}

D. lanata was grown with two seedlings in each pot (3.5"x3.5") in a growth chamber under a 16$\mathrm{h}$ light period at $25^{\circ} \mathrm{C}$. Treatments were applied to the true leaf pairs of the seedlings $5-6$ weeks after germination. $2 \mathrm{mM}$ methyl jasmonate (MJ), $1 \mathrm{mM} \mathrm{BTH,} 120 \mathrm{mM}$ sorbitol, $200 \mathrm{mM}$ potassium chloride $(\mathrm{KCl})$ and $5 \%(\mathrm{w} / \mathrm{v})$ yeast autolysate were administered by injecting the leaves through the lower epidermal layer symmetrically on both sides of the vein. $P$. syringae pv. tomato DC3000 was streaked out on a low-salt LB (Luria-Bertani) agar plate (10 g tryptone, $5 \mathrm{~g} \mathrm{NaCl}, 5 \mathrm{~g}$ yeast extract, and $15 \mathrm{~g}$ bacto agar per $1000 \mathrm{~mL}$ DI water) and incubated at $28^{\circ} \mathrm{C}$ for two days. A single colony was inoculated into $5 \mathrm{ml}$ low-salt LB broth $(10 \mathrm{~g}$ tryptone, $5 \mathrm{~g} \mathrm{NaCl}$, and $5 \mathrm{~g}$ yeast extract per $1000 \mathrm{~mL}$ DI water) with $50 \mathrm{mg} / \mathrm{L}$ rifampicin and grown at $30^{\circ} \mathrm{C}$ with shaking overnight. The seed culture was diluted to $\mathrm{OD}_{600}=0.1 \mathrm{in} 5 \mathrm{ml}$ low-salt $\mathrm{LB}+$ rifampicin and grown at $30^{\circ} \mathrm{C}$ until the $\mathrm{OD}_{600}$ reached 0.6 . The culture was spun down at $5,000 \mathrm{xg}$ for 5 min. The cell pellet was resuspended in $10 \mathrm{mM} \mathrm{MgCl}_{2}$ to a final $\mathrm{OD}_{600}$ of $0.1,0.01$, and 0.001 , respectively. The resulting bacterial suspensions were infiltrated into $D$. lanata, as mentioned above. For the wounding treatment, the lower epidermal surface of leaves was scratched with a needle multiple times. Biological triplicates were prepared from individual plants grown in separate pots. After $0,3,6,12$, and 24 hours, the leaves were cut off at the petiole and divided into two halves, with one half for HRLC/MS and the other half for qRT-PCR analysis. The collected leaves were immediately frozen in liquid nitrogen and stored at $-80^{\circ} \mathrm{C}$ until further analysis. 


\section{Preparation of plant extract}

The leaf samples for HRLC/MS analysis were freeze-dried for 24 hours using a Lab-conco FreeZone 2.5 lyophilizer (Kansas, Missouri). The dry weights of samples were recorded. The samples were then homogenized using plastic pestles (DWK life sciences, New Jersey) and dissolved in $1 \mathrm{ml}$ of $80 \%$ methanol with vortexing. The samples were then incubated at $65^{\circ} \mathrm{C}$ for $10 \mathrm{~min}$. The internal standard, digoxin-d3, was added at a final concentration of $50 \mathrm{nM}$ to the extracts. The samples were then centrifuged at 18,000xg for $2 \mathrm{~min}$, and the supernatant was filtered through a $0.45 \mu \mathrm{m}$ multiscreen filter plate (Merck Millipore, Carrigtwohill, Ireland). The samples were stored at $-20^{\circ} \mathrm{C}$ until $\mathrm{HRLC} / \mathrm{MS}$ analysis.

\section{Cardenolide quantification}

The cardenolides in leaf samples of different treatments were separated and analyzed using HRLC/MS as described previously (Ravi et al. 2020a). Briefly, a C18 HPLC column (Xselect $\mathrm{CSH}^{\mathrm{TM}}$, Waters, Milford, Massachusetts) $(3.5 \mu \mathrm{m}$ particle size, $2.1 \mathrm{~mm}$ i.d., $150 \mathrm{~mm}$ length) was used for separation on a Thermo Scientific Q-Exactive Focus ${ }^{\mathrm{TM}}$ Orbitrap with a mobile phase $\mathrm{A}$ containing water and $0.1 \%$ formic acid, and mobile phase B containing acetonitrile with $0.1 \%$ formic acid. An elution gradient started from $10 \%$ mobile phase B followed by a 12-min linear gradient to $95 \%$ mobile phase $B$ and held for $1 \mathrm{~min}$ at a flow rate of $200 \mu \mathrm{min}^{-1}$. The eluent was analyzed in the full-scan mode with an m/z range: 100-1200. Quantitative analysis was performed using the Xcalibur ${ }^{\mathrm{TM}}$ software. Relative abundance of cardenolides was calculated by dividing the peak area of individual cardenolides by the peak area of the internal standard. The relative abundance was then normalized by the dry weight of each sample. The percentage change in cardenolide levels was calculated by dividing the relative abundance of treated samples by the relative abundance of the controls.

\section{Quantitative real-time polymerase chain reaction ( $q R T-P C R$ )}

The RNA extraction from all the frozen leaf samples was done as described (Rio et al. 2010). The RNA isolated was converted to cDNA using the iScript ${ }^{\mathrm{TM}}$ cDNA synthesis kit following manufacturer's instruction. Primers for qRT-PCR analysis are in Table 1. The qRT-PCR reaction mix consisted of cDNA templates, primers, iTaq universal SYBR green master mix, and doubledistilled water with a final volume of $20 \mu \mathrm{L}$. The thermocycling included denaturation at $95^{\circ} \mathrm{C}$ for $3 \mathrm{~min}, 40$ cycles of denaturation at $95^{\circ} \mathrm{C}$ for $10 \mathrm{sec}$ and annealing at $55^{\circ} \mathrm{C}$ for $30 \mathrm{sec}$. A final melting step from $55^{\circ} \mathrm{C}$ to $95^{\circ} \mathrm{C}$ in $0.5^{\circ} \mathrm{C}$ increments for 81 cycles was used to generate melting curves. Three biological replicates and two technical replicates were used to measure gene expression. UBQ10 was the internal standard.

\begin{tabular}{|l|l|l|}
\hline $\begin{array}{l}\text { Gene } \\
\text { name }\end{array}$ & Forward primer & Reverse primer \\
\hline $3 \beta H S D$ & TAAGCATGTAGCTGAGGCGGC & CTAACGCACGACGGTGAAGC \\
\hline P5 $\beta$ R & AACTGAAGGATGTCGGAATTTGGTGG & GCCATGCTCCTTGCTCTTGTTC \\
\hline P5 $\beta$ R 2 & CAACATGGTTGATGAAATGGACA & CACCGTTTTGTGTCCTGC \\
\hline
\end{tabular}




\begin{tabular}{|l|l|l|}
\hline SSR1 & GACTGTACGAGAAGTGCAGGAGTAAG & GGAGTCTCGACAATAGCATTCTCAGC \\
\hline SMO3 & GCAGCTTACCACGATTACCACC & CTCCGTAACTTCCTTGTGGTACCG \\
\hline SMO1 & GTGGATTGCCATAAGACAGATTGAGG & GGTAATCTGGACCACCGTAGAATGG \\
\hline UBQ10 & CCCACCTGACCAGCAGAGATTG & ACCACCACGGAGACGTAGGAC \\
\hline
\end{tabular}

Table 1. Primer design for $D$. lanata $3 \beta \mathrm{HSD}, \mathrm{P} 5 \beta \mathrm{R}, \mathrm{P} 5 \beta \mathrm{R} 2, \mathrm{SMO}, \mathrm{SSR}$, and UBQ10 genes.

\section{Correlation analysis}

The Social Science Statistics website < https://www.socscistatistics.com/ > was used to calculate the Pearson's correlation coefficients (PCC) between the cardenolide levels and the gene expression levels. PCC is a linear correlation coefficient with a value between -1 (strong negative correlation) and 1 (strong positive correlation). PCC with a value $>0.7$ and $p$-value $<0.1$ was considered a significant positive correlation.

De novo assembly of transcriptome

First true leaves and whole root from 5 weeks old seedlings of $D$. lanata were used for transcriptome assembly. Tissues from 3 separate seedlings were pooled together for each sample and 6 such samples were prepared. Total RNA was isolated using RNeasy Plant Mini Kit (QIAGEN, Maryland, USA) following the manufacturer's protocol. The sequencing library was prepared using the TrueSeq Ribo-Zero Plant RNA library prep kit (Illumina, California, USA). Quality check of the library was carried out on an Agilent 2100 bioanalyzer. The library was sequenced using Illumina HiSeq 2500 to generate $100 \mathrm{bp}$ paired end raw reads at Genomics and Bioinformatics Core in University at Buffalo. The average sequencing depth is 14.5M reads per sample.

FastQC (v0.11.5) was used for quality check of the high throughput sequence data (Andrews 2010). De novo assembly of a single transcriptome (leaf and root) from the raw reads was done using Trinity assembler program (v2.8.4) at the default k-mer value of 25 (Haas et al. 2013). The overall quality of the transcriptome was ascertained using the standard N50 and ExN50 values.

Mining the transcriptome for cholesterol and phytosterol biosynthesis genes

Firstly, the open reading frames (ORFs) and their corresponding protein sequences were identified from the transcriptome using the TransDecoder tool in the Trinity pipeline. Identification of the unigenes (unique ORFs) was carried out using CD-HIT-EST (v4.6.8) with an identity threshold of $99 \%$, a word length of 10 (the size of the sequence used in each cycle of comparison), and with the mode to cluster the most similar sequences (Li and Godzik 2006). Further, protein sequences of the SSR1, SMO3 and SMO1 genes from tomato were used to query the transcriptome using tBLASTN. The SSR1, SMO3 and SMO1 genes of D. lanata were narrowed down to the unigenes identified from the transcripts which resulted from the respective tBLASTN hits.

\section{Phylogenetic tree construction}


The protein sequences were aligned using MUSCLE in MEGAX (Stecher et al. 2020). The maximum likelihood tree was created using RAxML-NG (1.0.1) with the all-in-one ML tree search and slow bootstrapping on the CIPRES portal (Miller et al. 2010). Bootstrap values are represented at the nodes as a percentage of 1000 replicates. In the SMO tree, S. cerevisiae ERG25 was used as an outgroup. In the SSR tree, the human delta (24)-sterol reductase was used as the outgroup.

\section{Results:}

Identify stressors that increase cardenolides in D. lanata.

Plant secondary metabolite concentrations are known to increase under stresses. Therefore, we studied cardenolide levels under different stresses. Leaf lanatosides were measured by $\mathrm{HRLC} / \mathrm{MS} 24 \mathrm{~h}$ after treatments. MJ, sorbitol, $\mathrm{BTH}$, and $\mathrm{KCl}$ significantly increased total lanatosides while wounding, yeast autolysate, and $P$. syringae did not (Figure 2). These results indicate that cardenolides are involved in stress responses in D. lanata.

\section{Expression of cardenolide biosynthetic genes during stresses}

Next, the expression levels of $3 \beta \mathrm{HSD}, \mathrm{P} 5 \beta \mathrm{R}$ and $\mathrm{P} 5 \beta \mathrm{R} 2$, and the total cardenolide levels were measured at different time points following effective treatments with MJ, sorbitol and BTH. Although $\mathrm{KCl}$ increased lanatosides, it was not included in this follow-up experiment because it likely exerted similar osmotic stress as sorbitol. Cardenolides analyzed were expanded from the four lanatosides to 17 cardenolides we had characterized previously (Ravi et al. 2020b), (Ravi et al. 2020a).

After MJ treatment, total cardenolide increased significantly at $3 \mathrm{~h}$. This increase was observed for all cardenolides detected (Figure 3A). Total cardenolides increased over two folds compared to the control at $3 \mathrm{~h}$, followed by a sharp decrease to the control level at $6 \mathrm{~h}$ (Figure $3 \mathrm{~B}$ ). Gene expressions of $3 \beta \mathrm{HSD}, \mathrm{P} 5 \beta \mathrm{R}$, and $\mathrm{P} 5 \beta \mathrm{R} 2$ did not correlate with the total cardenolide levels according to the calculated Pearson correlation coefficients (PCC) (Figure 3C). Although P5 $\beta$ R's expression seemed to correlate, the p-value of this PCC is 0.12 , which was insignificant.

After sorbitol treatment, total cardenolide levels dropped first, followed by an increase. All individual cardenolides seemed to follow this trend (Figure 4A). Like the MJ treatment, gene expressions for $3 \beta \mathrm{HSD}, \mathrm{P} 5 \beta \mathrm{R}$, and $\mathrm{P} 5 \beta \mathrm{R} 2$ did not parallel the changes of cardenolides (Figure $4 \mathrm{C})$. Hence, Fluctuations of total cardenolide after sorbitol treatment could not be explained by the expression levels of these three genes.

BTH treatment increased the total cardenolides two folds at $3 \mathrm{~h}$, followed by a steady decrease to the control level after $12 \mathrm{~h}$. Interestingly, the increase was mainly driven by the "early cardenolides", including glucodigifucoside and glucolanadoxin (Figure 5A). "Early cardenolides" were produced early in $D$. lanata's development. They were disaccharides with mainly fucose or digitalose moieties. The more common tetrasaccharides, including lanatosides, were called "late cardenolides” (Kreis 2017), (Eisenbeiß et al. 1999). Regarding gene expression, 3ßHSD's 
expression increased five folds at $3 \mathrm{~h}$, followed by a sharp decrease to the control level at $6 \mathrm{~h}$ (Figure $5 \mathrm{C}$ ). This change was correlated with total cardenolide increase at $3 \mathrm{~h}$ ( $\mathrm{PCC}=0.85$, $\mathrm{p}=0.07$ ). $\mathrm{P} 5 \beta \mathrm{R}$ and $\mathrm{P} 5 \beta \mathrm{R} 2$ 's expressions were not correlated with total cardenolide levels. Therefore, $3 \beta \mathrm{HSD}$ was likely responsible for the cardenolide increase after BTH treatment.

\section{Expression of sterol biosynthetic genes during stresses}

We identified potential rate-limiting genes for sterol biosynthesis by mining a de novo assembled $D$. lanata transcriptome: SMO1 and SSR1. In addition, we found SMO1 was duplicated into SMO3, which is specialized in cholesterol biosynthesis in Solanum species (Sonawane et al. 2016). After BTH treatment, the expression of SSR1, SMO1, and SMO3 significantly correlated with total cardenolide levels ( $P C C=0.92,0.81$, and 0.86 , respectively) with p-values < 0.1 (Figure 6). Under BTH stress, there was a four-fold increase in SSR1 and SMO3 expression and a 2.5-fold increase in SMO1 expression at $3 \mathrm{~h}$, following which their expressions declined to control levels. This trend matched the 2-fold increase of total cardenolide at $3 \mathrm{~h}$ followed by a decline to the control level. The correlation of cardenolide production with the sterol pathway genes indicated that phytosterols could potentially serve as the precursor(s) for the cardenolide biosynthesis. However, the expressions of these genes did not correspond with cardenolides after MJ or sorbitol treatments.

\section{Cholesterol and phytosterol biosynthetic pathways in D. lanata}

Identifying the SMO3 gene prompted us to search for other duplicated sterol biosynthetic genes in $D$. lanata. However, we were unable to find any other phytosterol gene duplications besides $\mathrm{SMO} 3$ in the transcriptome, indicating that the cholesterol biosynthesis in D. lanata may only deviate from phytosterol biosynthesis at the rate-limiting $\mathrm{C} 4$ sterol methyl oxidase step. This is supported by the fact that cholesterol level is not exceptionally high in $D$. lanata compared to other plant species (Milek et al. 1997), (Kumar et al. 2021). Duplication of SMO1 indicates that SMO1 is likely specific for phytosterol biosynthesis while SMO3 is specific for cholesterol biosynthesis, and SSR1 may be involved in both pathways (Figure 7A). Phylogenetic analysis showed that other species in Lamiales also have the duplicated C4 sterol methyl oxidase SMO3 but lack the duplicated C24 sterol sidechain reductase SSR2 (Figure 7B\&C). These two enzymes are not duplicated in other plant species such as Arabidopsis, rice, maize, grape, etc. These results suggest that cholesterol biosynthesis in Lamiales seems to be separated from phytosterol biosynthesis only at the rate-limiting C4 sterol methyl oxidase step.

\section{Discussion}

In this work, we studied total cardenolide levels in response to different stress treatments. We also attempted to reveal the molecular mechanism underlining this response. We found that MJ, sorbitol, $\mathrm{KCl}$, and $\mathrm{BTH}$ treatments transiently increased cardenolide levels in the leaves of $D$. lanata. Among the three known cardenolide biosynthetic genes, only 3 $\beta$ HSD's expression corresponded well with cardenolide increase during the BTH treatments. In contrast, P5 $\beta$ R and P5 $\beta R 2$ 's expression did not correlate with cardenolides in any effective treatments. Additionally, 
we identified enzymes involved in cholesterol and phytosterol biosynthesis: SSR1, SMO3, and SMO1. Their expressions were also highly correlated with cardenolide increase after the BTH treatment.

Previous works have reported the increase of cardenolides in foxglove and other species under various stress conditions. Our analysis differs from others by using a highly sensitive LC/MS method to profile a broader range of cardenolides, including both early and late glycosides (Ravi et al. 2020b), (Ravi et al. 2020a). Patil et al. reported the increase of digoxin and digitoxin in $D$. purpura, a closely related species to $D$. lanata, with salicylic acid, mannitol, sorbitol, and $\mathrm{KCl}$ elicitation, and lack of increase with yeast autolysate (Patil et al. 2013). Their findings corroborate well with our studies in $D$. lanata. In another study, wounding also elevated cardenolides in $D$. purpurea, which we did not observe in D. lanata (Pérez-Bermúdez et al. 2010). Additionally, $\mathrm{H}_{2} \mathrm{O}_{2}$ increased cardenolides in four species of foxglove plants (Cingoz et al. 2014). In other species which also accumulate cardenolides, such as Calotropis procera and Erysimum crepidifolium, stress treatments also led to cardenolide increase ((Pandey et al. 2016), (Munkert et al. 2014)). Therefore, the roles cardenolides play in defense are likely generalizable in plants.

Few genes of the $D$. lanata cardenolide pathway have been identified so far, including $3 \beta H S D$, P5ßR, and P5ßR2 (Seidel et al. 1990), (Gärtner et al. 1990), (Pérez-Bermúdez et al. 2010). Although 3 $\beta$ HSD's expression strongly correlated with cardenolide increase after the BTH treatment, $\mathrm{P} 5 \beta \mathrm{R}$ and $\mathrm{P} 5 \beta \mathrm{R} 2$ did not correlate. $3 \beta \mathrm{HSD}$ belongs to the prokaryotic short-chain dehydrogenase/reductase superfamily and putatively catalyzes two steps in the cardenolide biosynthetic pathway (Figure 1). $3 \beta \mathrm{HSD}$ was also stress-inducible in Erysimum crepidifolium

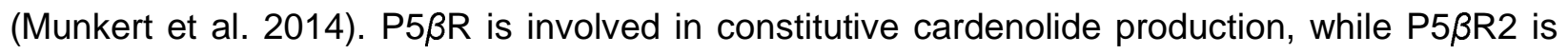
expressed transiently under stresses (Klein et al. 2021). Previous work showed that P5 $\beta$ R2's expression was upregulated by $\mathrm{H}_{2} \mathrm{O}_{2}$ and ethylene treatments but not MJ and $\mathrm{SA}$ treatments in D. purpurea, which agrees with our observations in D. lanata (Pérez-Bermúdez et al. 2010). The overall lack of correlation between $\mathrm{P} 5 \beta \mathrm{R}$ gene expression and cardenolide levels might be because $\mathrm{P} 5 \beta \mathrm{R}$ s are extremely promiscuous enzymes that also function as iridoid synthase in many lineages of land plants (Munkert et al. 2015), (Schmidt et al. 2018), (Nguyen and O'Connor 2020).

Our study identified the putative genes for sterol synthesis in D. lanata, and suggested the involvement of the phytosterol pathway in cardenolide biosynthesis. According to a recent study in tomatoes, the $\mathrm{SMO} 3$ is specialized for cholesterol biosynthesis and SMO1 is specific to phytosterol biosynthesis (Sonawane et al. 2016). Therefore, it is likely that SMO3 in D. lanata is dedicated to cholesterol biosynthesis, and SMO1 is specific to phytosterol biosynthesis. In Solanum species, SSR1 is specialized for phytosterol biosynthesis, and SSR2 is involved exclusively in cholesterol biosynthesis. The lack of an SSR2 in the D. lanata transcriptome suggested that SSR1 may be involved in both pathways. The strong positive correlation of SMO3, SMO1, and SSR1's expression levels with total cardenolides after the BTH treatment indicates that the cardenolide biosynthesis uses both cholesterol and phytosterols as 
substrates. This notion is tentative because a direct relationship between the sterol biosynthetic genes' induction and cardenolide increase has yet to be established.

None of the six genes tested correlated with the cardenolide increase after MJ and sorbitol treatments. However, four out of six showed a positive correlation with cardenolide levels after the BTH treatment. This result suggests that the increase of cardenolides after MJ or sorbitol treatment is regulated differently from the increase after the BTH treatment. Indeed, MJ and salicylic acid signaling pathways are often antagonistic to each other (Niki et al. 1998), (Mur et al. 2006). Our results also showed that the MJ treatment increased both "early-type" and "latetype" cardenolides. However, the BTH treatment mainly increased the "early-type" cardenolides. Identifying $D$. lanata genes that correlate with cardenolide levels after MJ treatment will reveal the missing genes involved in the cardenolide biosynthetic pathway.

In conclusion, this work has provided molecular insights into the stress responses that led to the increased cardenolides in $D$. lanata. It is also suggested that besides cholesterol, phytosterols may also be substrates for cardenolide biosynthesis. Transcriptomic analysis of global gene expressions after MJ or BTH treatment in the future will likely identify novel genes responsible for cardenolide biosynthesis.

\section{Acknowledgment}

The authors are grateful to the mass spectrometry support from the Chemistry Instrument Center and the Genomics and Bioinformatics Core at University at Buffalo. This work was supported by funding from the Research Foundation for the State University of New York (71272) to Z.Q.W.

\section{Competing financial interests}

The authors declare no competing financial interests.

\section{REFERENCES:}

Agrawal, A.A., Petschenka, G., Bingham, R.A., Weber, M.G., and Rasmann, S. (2012) Toxic cardenolides: chemical ecology and coevolution of specialized plant-herbivore interactions. New Phytologist 194: 28-45.

Andrews, S. (2010) FastQC: a quality control tool for high throughput sequence data. Babraham Bioinformatics, Babraham Institute, Cambridge, United Kingdom.

Bertol, J.W., Rigotto, C., de Pádua, R.M., Kreis, W., Barardi, C.R.M., Braga, F.C., et al. (2011) Antiherpes activity of glucoevatromonoside, a cardenolide isolated from a Brazilian cultivar of Digitalis lanata. Antiviral Research 92: 73-80.

Bókony, V., Üveges, B., Verebélyi, V., Ujhegyi, N., and Móricz, Á.M. (2019) Toads phenotypically adjust their chemical defences to anthropogenic habitat change. Scientific Reports 9: 3163. 
Calderón-Montaño, J.M., Burgos-Morón, E., Orta, M.L., Maldonado-Navas, D., GarcíaDomínguez, I., and López-Lázaro, M. (2014) Evaluating the cancer therapeutic potential of cardiac glycosides. BioMed Research International 2014: 794930

Cingoz, G.S., and Gurel, E. (2016) Effects of salicylic acid on thermotolerance and cardenolide accumulation under high temperature stress in Digitalis trojana Ivanina. Plant Physiology and Biochemistry 105: 145-149.

Cingoz, G.S., Verma, S.K., and Gurel, E. (2014) Hydrogen peroxide-induced antioxidant activities and cardiotonic glycoside accumulation in callus cultures of endemic Digitalis species. Plant Physiology and Biochemistry 82: 89-94.

Eisenbeiß, M., Kreis, W., and Reinhard, E. (1999) Cardenolide biosynthesis in light-and darkgrown Digitalis lanata shoot cultures. Plant Physiology and Biochemistry 37: 13-23.

Fonin, V., and Ala, K. (2003) Preparation of biologically transformed raw material from woolly foxglove Digitalis lanata Ehrh and isolation of digoxin from it. Prikladnaia Biokhimiia $i$ Mikrobiologiia 39: 588-592.

Gärtner, D.E., Wendroth, S., and Seitz, H.U. (1990) A stereospecific enzyme of the putative biosynthetic pathway of cardenolides: Characterization of a progesterone $5 \beta$-reductase from leaves of Digitalis purpurea L. FEBS Letters 271: 239-242.

Gurel, E., Karvar, S., Yucesan, B., Eker, I., and Sameeullah, M. (2017) An overview of cardenolides in digitalis-more than a cardiotonic compound. Current Pharmaceutical Design 23: 5104-5114.

Haas, B.J., Papanicolaou, A., Yassour, M., Grabherr, M., Blood, P.D., Bowden, J., et al. (2013) De novo transcript sequence reconstruction from RNA-seq using the Trinity platform for reference generation and analysis. Nature Protocols 8: 1494-1512.

Hamlyn, J.M., Blaustein, M., Bova, S., DuCharme, D., Harris, D., Mandel, F., et al. (1991) Identification and characterization of a ouabain-like compound from human plasma. Proceedings of the National Academy of Sciences 88: 6259-6263.

Haux, J., Solheim, O., Isaksen, T., and Angelsen, A. (2000) Digitoxin, in non-toxic concentrations, inhibits proliferation and induces cell death in prostate cancer cell lines. Zeitschrift für Onkologie 32: 11-16.

Herl, V., Fischer, G., Müller-Uri, F., and Kreis, W. (2006) Molecular cloning and heterologous expression of progesterone 5ß-reductase from Digitalis lanata Ehrh. Phytochemistry 67: 225231.

Herl, V., Frankenstein, J., Meitinger, N., Müller-Uri, F., and Kreis, W. (2007) $\Delta 5-3 \beta-$ Hydroxysteroid dehydrogenase (3ßHSD) from Digitalis lanata. Heterologous expression and characterisation of the recombinant enzyme. Planta Medica 73: 704-710.

Klein, J., Horn, E., Ernst, M., Leykauf, T., Leupold, T., Dorfner, M., et al. (2021) RNAi-mediated gene knockdown of progesterone $5 \beta$-reductases in Digitalis lanata reduces $5 \beta$-cardenolide content. Plant Cell Reports 40: 1631-1646.

Kreis, W. (2017) The foxgloves (Digitalis) revisited. Planta Medica 83: 962-976.

Kumar, K., Gibbs, H.C., Yeh, A.T., and Griffing, L.R. (2021) The sterol trafficking pathway in Arabidopsis thaliana. Frontiers in Plant Science 12: 616631. 
Lange, I., Poirier, B.C., Herron, B.K., and Lange, B.M. (2015) Comprehensive assessment of transcriptional regulation facilitates metabolic engineering of isoprenoid accumulation in Arabidopsis. Plant Physiology 169: 1595-1606.

Li, W., and Godzik, A. (2006) Cd-hit: A fast program for clustering and comparing large sets of protein or nucleotide sequences. Bioinformatics 22: 1658-1659.

Ludens, J.H., Clark, M.A., DuCharme, D., Harris, D.W., Lutzke, B.S., Mandel, F., et al. (1991) Purification of an endogenous digitalislike factor from human plasma for structural analysis. Hypertension 17: 923-929.

Manna, S.K., Sreenivasan, Y., and Sarkar, A. (2006) Cardiac glycoside inhibits IL-8-induced biological responses by downregulating IL-8 receptors through altering membrane fluidity. Journal of Cellular Physiology 207: 195-207.

Mathews, W.R., DuCharme, D.W., Hamlyn, J.M., Harris, D.W., Mandel, F., Clark, M.A., et al. (1991) Mass spectral characterization of an endogenous digitalislike factor from human plasma. Hypertension 17: 930-935.

Mekhail, T., Kaur, H., Ganapathi, R., Budd, G.T., Elson, P., and Bukowski, R.M. (2006) Phase 1 trial of Anvirzel ${ }^{\mathrm{TM}}$ in patients with refractory solid tumors. Investigational New Drugs 24: 423427.

Mijatovic, T., Mathieu, V., Gaussin, J.-F., De Néve, N., Ribaucour, F., Van Quaquebeke, E., et al. (2006) Cardenolide-induced lysosomal membrane permeabilization demonstrates therapeutic benefits in experimental human non-small cell lung cancers. Neoplasia 8: 402-412.

Milek, F., Reinhard, E., Kreis, W. (1997) Influence of precursors and inhibitors of the sterol pathway on sterol and cardenolide metabolism in Digitalis lanata Ehrh. Plant Physiology and Biochemistry 35: 111-121.

Miller, M., Pfeiffer, W., and Schwartz, T. (2010) Creating the CIPRES science gateway for inference of large phylogenetic trees, p 11572-8. In Proceedings of the Gateway Computing Environments Workshop (GCE). Institute of Electrical and Electronics Engineers, Piscataway, NJ. doi. org/10.1109/GCE.

Munkert, J., Ernst, M., Müller-Uri, F., and Kreis, W. (2014) Identification and stress-induced

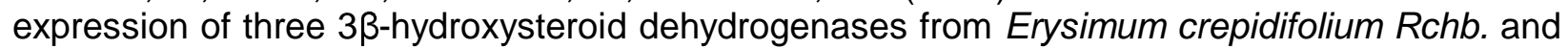
their putative role in cardenolide biosynthesis. Phytochemistry 100: 26-33.

Munkert, J., Pollier, J., Miettinen, K., Van Moerkercke, A., Payne, R., Müller-Uri, F., et al. (2015) Iridoid synthase activity is common among the plant progesterone $5 \beta$-reductase family. Molecular Plant 8: 136-152.

Mur, L.A., Kenton, P., Atzorn, R., Miersch, O., and Wasternack, C. (2006) The outcomes of concentration-specific interactions between salicylate and jasmonate signaling include synergy, antagonism, and oxidative stress leading to cell death. Plant Physiology 140: 249-262.

Nguyen, T.-D., and O'Connor, S.E. (2020) The progesterone 5ß-reductase/Iridoid synthase family: a catalytic reservoir for specialized metabolism across land plants. ACS Chemical Biology 15: 1780-1787.

Niki, T., Mitsuhara, I., Seo, S., Ohtsubo, N., and Ohashi, Y. (1998) Antagonistic effect of salicylic acid and jasmonic acid on the expression of pathogenesis-related (PR) protein genes in wounded mature tobacco leaves. Plant and Cell Physiology 39: 500-507.

World Health Organizations, (2013) WHO model list of essential medicines: 18th list, April 2013. 
Palazón, J., Bonfill, M., Cusidó, R.M., Pinol, M., and Morales, C. (1995) Effects of auxin and phenobarbital on morphogenesis and production of digitoxin in Digitalis callus. Plant and Cell Physiology 36: 247-252.

Pandey, A., Swarnkar, V., Pandey, T., Srivastava, P., Kanojiya, S., Mishra, D.K., et al. (2016) Transcriptome and metabolite analysis reveal candidate genes of the cardiac glycoside biosynthetic pathway from Calotropis procera. Scientific Reports 6: 1-14.

Patil, J.G., Ahire, M.L., Nitnaware, K.M., Panda, S., Bhatt, V.P., Kishor, P.B.K., et al. (2013) In vitro propagation and production of cardiotonic glycosides in shoot cultures of Digitalis purpurea L. by elicitation and precursor feeding. Applied Microbiology and Biotechnology 97: 2379-2393.

Pérez-Bermúdez, P., Moya Garcia, A.A., Tuñón, I., and Gavidia, I. (2010) Digitalis purpurea P5 $\beta R 2$, encoding steroid $5 \beta$-reductase, is a novel defense-related gene involved in cardenolide biosynthesis. New Phytologist 185: 687-700.

Piccioni, F., Roman, B.R., Fischbeck, K.H., and Taylor, J.P. (2004) A screen for drugs that protect against the cytotoxicity of polyglutamine-expanded androgen receptor. Human Molecular Genetics 13: 437-446.

Prassas, I., and Diamandis, E.P. (2008) Novel therapeutic applications of cardiac glycosides. Nature Reviews Drug Discovery 7: 926-935.

Ravi, B.G., Guardian, M.G.E., Dickman, R., and Wang, Z.Q. (2020a) High-resolution tandem mass spectrometry dataset reveals fragmentation patterns of cardiac glycosides in leaves of the foxglove plants. Data in Brief 30: 105464.

Ravi, B.G., Guardian, M.G.E., Dickman, R., and Wang, Z.Q. (2020b) Profiling and structural analysis of cardenolides in two species of Digitalis using liquid chromatography coupled with high-resolution mass spectrometry. Journal of Chromatography A 1618: 460903.

Rio, D.C., Ares, M., Hannon, G.J., and Nilsen, T.W. (2010) Purification of RNA using TRIzol (TRI reagent). Cold Spring Harbor Protocol 2010: pdb. prot5439.

Schmidt, K., Petersen, J., Munkert, J., Egerer-Sieber, C., Hornig, M., Muller, Y.A., et al. (2018) PRISEs (progesterone 5ß-reductase and/or iridoid synthase-like 1, 4-enone reductases): catalytic and substrate promiscuity allows for realization of multiple pathways in plant metabolism. Phytochemistry 156: 9-19.

Schneider, N.F., Geller, F.C., Persich, L., Marostica, L.L., Pádua, R.M., Kreis, W. et al., (2016) Inhibition of cell proliferation, invasion and migration by the cardenolides digitoxigenin monodigitoxoside and convallatoxin in human lung cancer cell line. Natural Product Research 30: 1327-1331.

Seidel, S., Kreis, W., and Reinhard, E. (1990) $\Delta 5-3 \beta$-Hydroxysteroid dehydrogenase $/ \Delta 5-\Delta 4-$ ketosteroid isomerase (3ß-HSD), a possible enzyme of cardiac glycoside biosynthesis, in cell cultures and plants of Digitalis lanata Ehrh. Plant Cell Reports 8: 621-624.

Sonawane, P.D., Pollier, J., Panda, S., Szymanski, J., Massalha, H., Yona, M., et al. (2016) Plant cholesterol biosynthetic pathway overlaps with phytosterol metabolism. Nature Plants 3: 113.

Srivastava, M., Eidelman, O., Zhang, J., Paweletz, C., Caohuy, H., Yang, Q. et al., (2004) Digitoxin mimics gene therapy with CFTR and suppresses hypersecretion of IL-8 from cystic fibrosis lung epithelial cells. Proceedings of the National Academy of Sciences 101: 7693-7698. 
bioRxiv preprint doi: https://doi.org/10.1101/2021.09.27.461964; this version posted September 27, 2021. The copyright holder for this preprint (which was not certified by peer review) is the author/funder, who has granted bioRxiv a license to display the preprint in perpetuity. It is made available under aCC-BY-NC-ND 4.0 International license.

Stecher, G., Tamura, K., and Kumar, S. (2020) Molecular evolutionary genetics analysis (MEGA) for macOS. Molecular Biology and Evolution 37: 1237-1239.

Valitova, J., Sulkarnayeva, A., and Minibayeva, F. (2016) Plant sterols: diversity, biosynthesis, and physiological functions. Biochemistry (Moscow) 81: 819-834.

Wang, Z., Zheng, M., Li, Z., Li, R., Jia, L., Xiong, X., et al. (2009) Cardiac glycosides inhibit p53 synthesis by a mechanism relieved by Src or MAPK inhibition. Cancer Research 69: 6556-6564. 


\section{Figures}

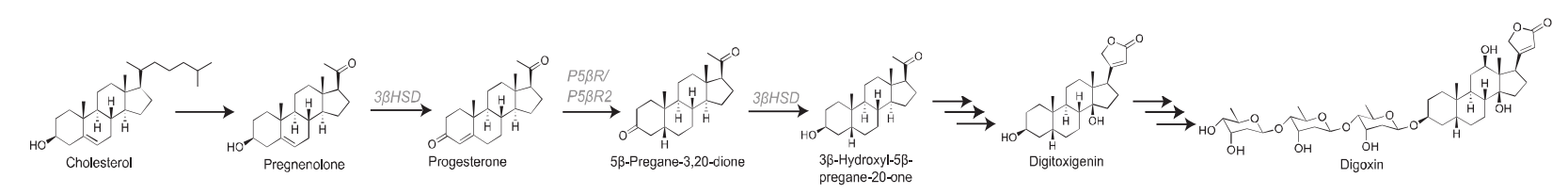

Figure 1. Cardenolide biosynthetic pathway in $D$. lanata. $3 \beta-H S D$ and P5RR/P5 $3 R 2$ are the known enzymes involved in this process. $3 \beta$-HSD: $3 \beta$-hydroxysteroid dehydrogenase; P5 $\beta$ R/P5 $\beta$ R2: progesterone $5 \beta$-reductase.

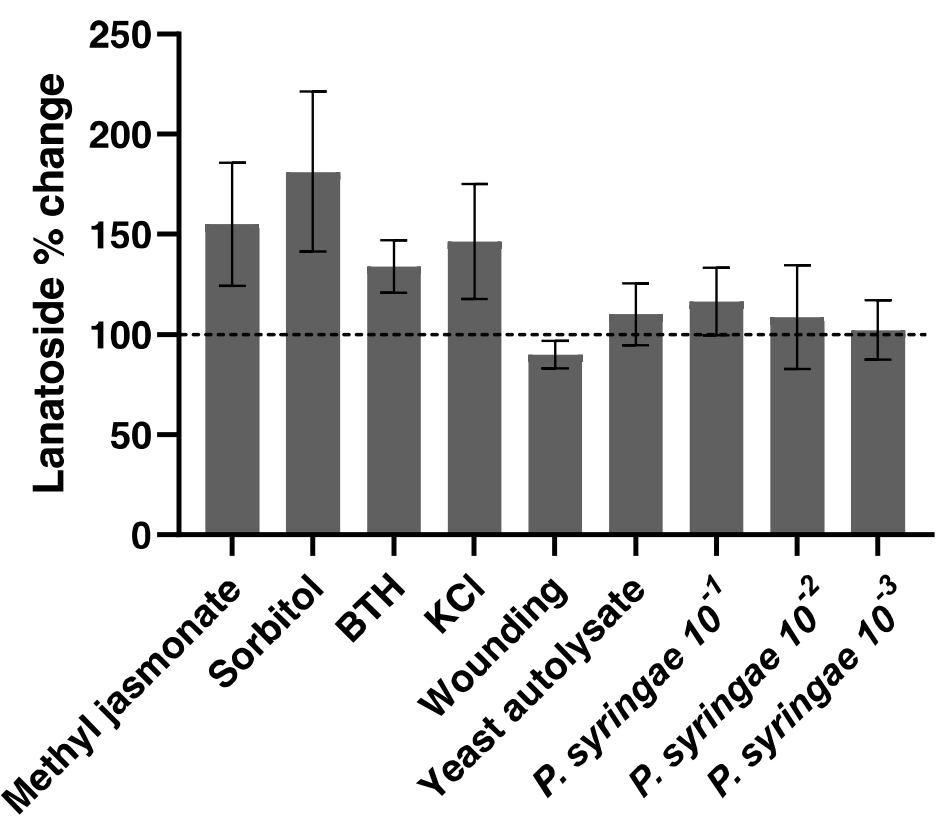

Figure 2. Increase of total lanatosides after different stresses in D. lanata. Levels of lanatosides $\mathrm{A}, \mathrm{B}, \mathrm{C}$, and $\mathrm{E}$ were quantified by HRLC/MS $24 \mathrm{~h}$ after treatments. The dashed line represents total lanatoside levels in the untreated leaves. BTH: 2,1,3-Benzothiadiazole. $P$. syringae was infiltrated at $\mathrm{OD}_{600}=0.1,0.01$, and 0.001 respectively. Error bars represent the standard deviation of three biological replicates. 
A

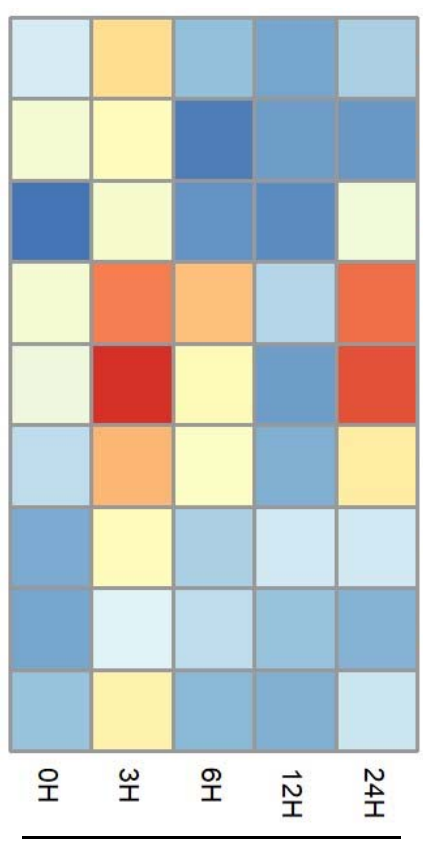

after MJ treatment
B

350

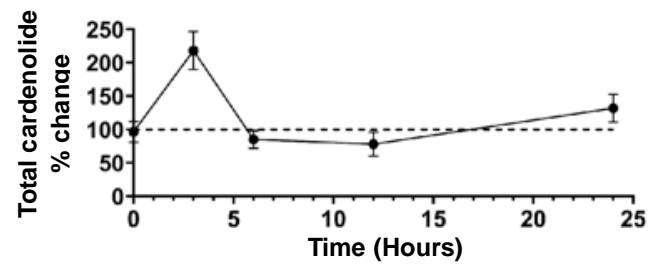

250

C

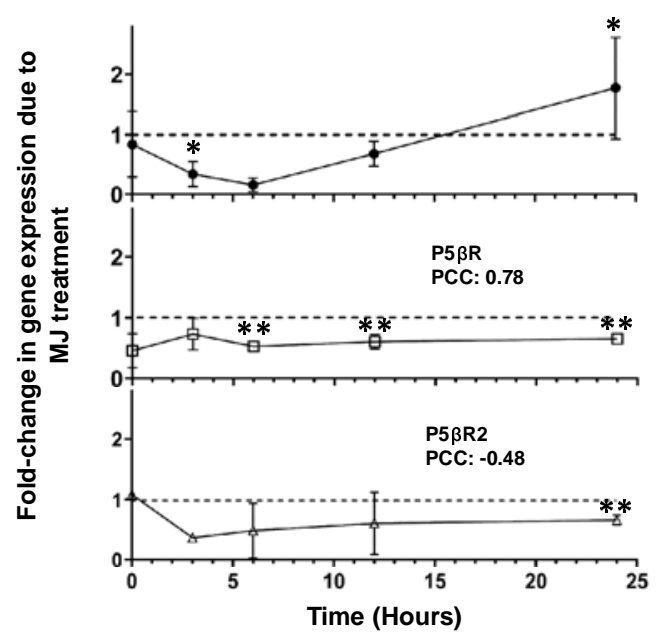

Figure 3. Time-resolved changes in cardenolide levels and related gene expressions after the MJ treatment. A. Changes in individual cardenolide levels over time quantified by HRLC/MS. B. Changed in total cardenolide levels over time. C. Changes in relative gene expression levels over time determined by qRT-PCR. The dashed lines represent levels in the untreated controls. Pearson's Correlation Coefficient (PCC) values indicate the extent of correlation between changes in cardenolide levels and changes in gene expressions. Error bars represent the standard deviations of three biological replicates. ${ }^{*}: p<0.05 ;{ }^{* *}: p<0.01$. 


\section{A}

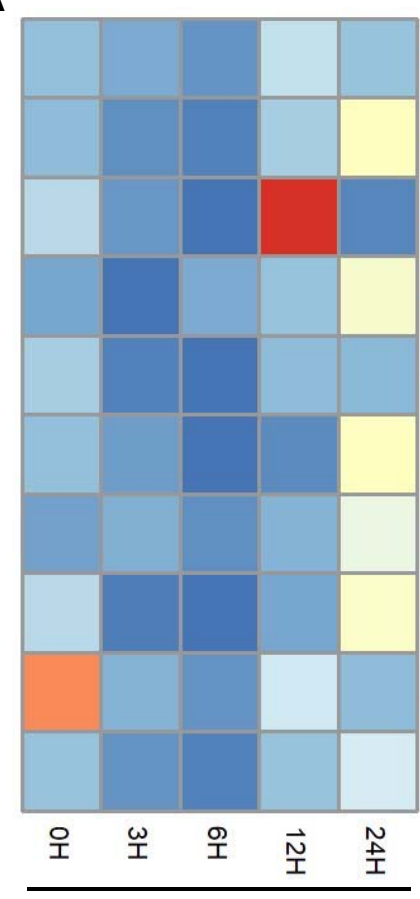

after sorbitol treatment
B

400

Glucodigifucoside

Odorobioside G

Glucolanadoxin

Lanatoside C

Lanatoside B

Lanatoside $\mathrm{E}$

Lanatoside A

a/b-Acetyldigitoxin

Total cardenolides

100

C
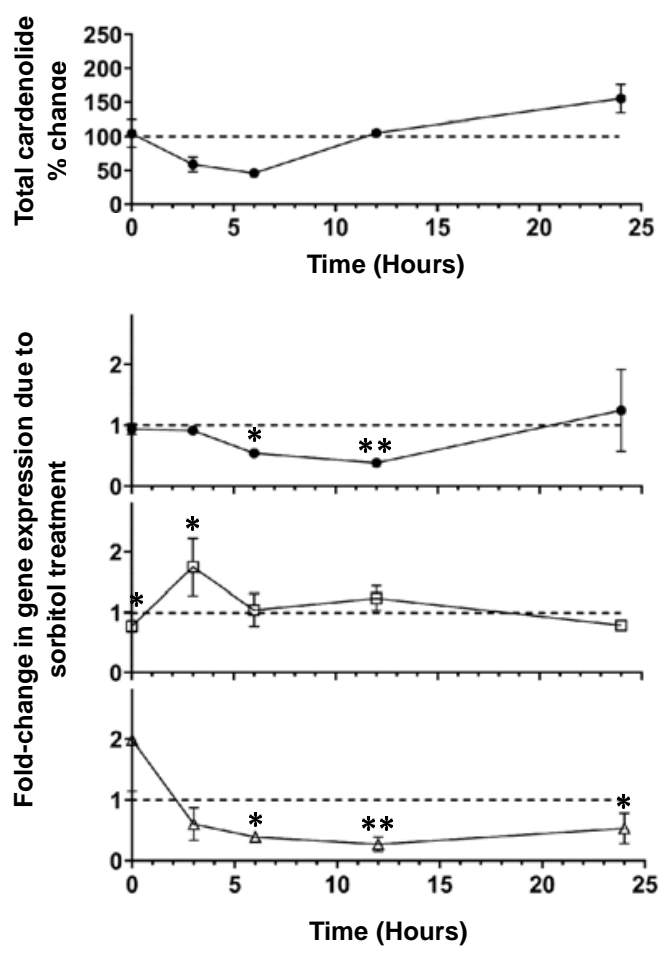

Figure 4. Time-resolved changes in cardenolide levels and related gene expressions after the sorbitol treatment. A. Changes in individual cardenolide levels over time. B. Changes in total cardenolide levels over time. C. Changes in relative gene expression levels over time. PCC values indicate the extent of correlation between changes in cardenolide levels and changes in gene expressions. Error bars represent the standard deviations of three biological replicates. *: $p<0.05 ;{ }^{* *}: p<0.01$. 
A

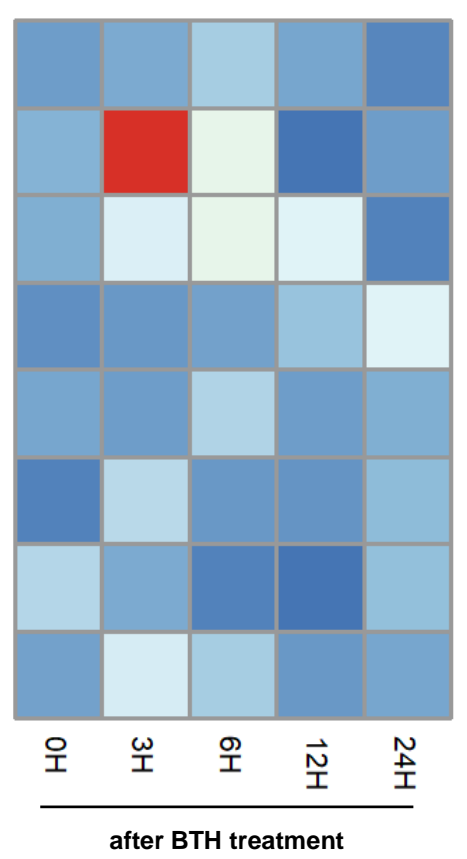

B
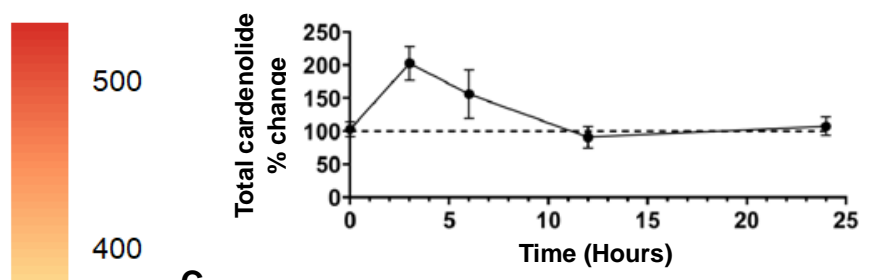

Lanatoside B

Lanatoside $\mathrm{E}$

Lanatoside A

a/b-Acetyldigitoxin

Total cardenolides

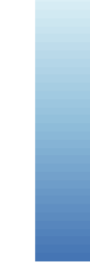

C

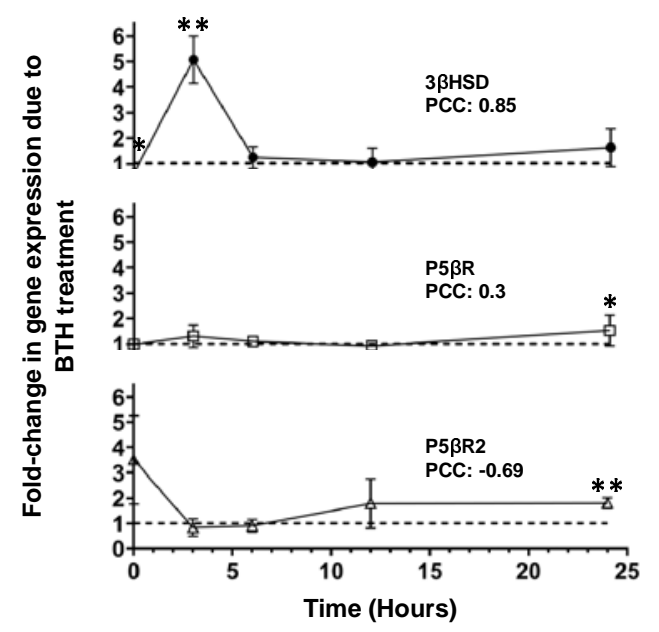

Figure 5. Time-resolved changes in cardenolide levels and related gene expressions after the BTH treatment. A. Changes in individual cardenolide levels over time. B. Changes in total cardenolide levels over time. C. Changes in relative gene expression levels over time. PCC values indicate the extent of correlation between changes in cardenolide levels and changes in gene expressions. Error bars represent the standard deviations of three biological replicates. *: $p<0.05 ;{ }^{* *}: p<0.01$. 
A
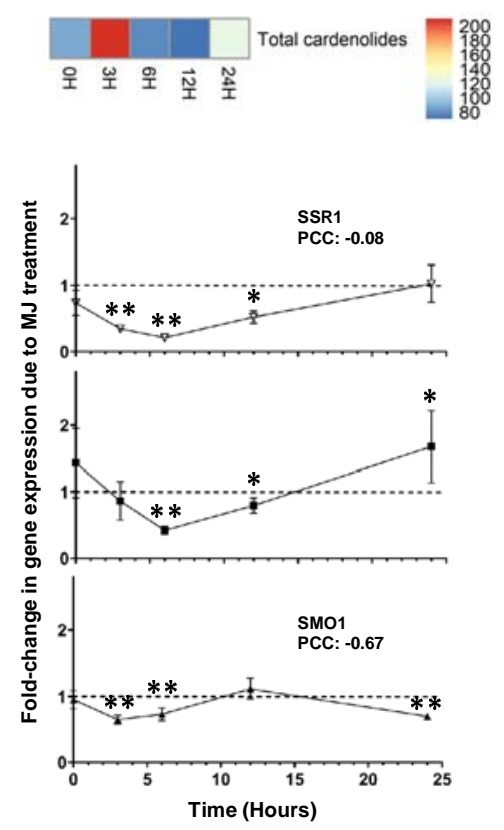

B
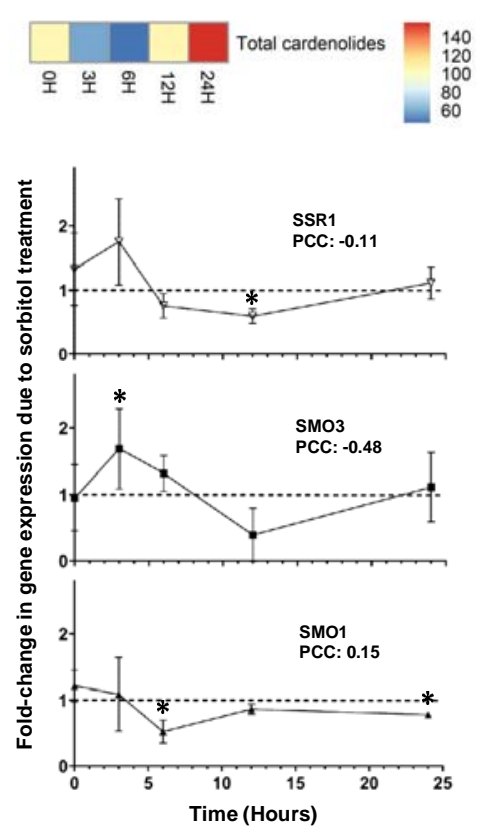

C
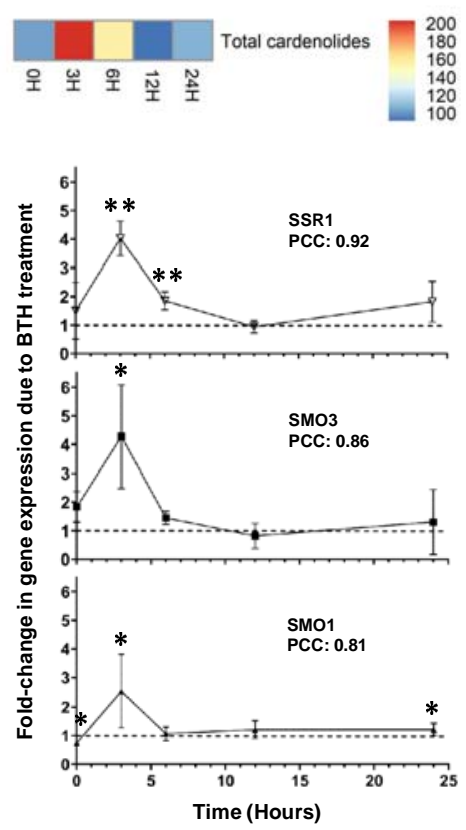

Figure 6. Changes in total cardenolide levels and expressions of phytosterol biosynthetic genes after stress treatments. A. Time-resolved changes after the MJ treatment. B. Time-resolved changes after the sorbitol treatment. C. Time-resolved changes after the BTH treatment. SSR1: sterol sidechain reductase; SMO: C4 sterol methyl oxidase. PCC values indicate the extent of correlation between changes in cardenolide levels and gene expression. Error bars represent the standard deviations of three biological replicates. ${ }^{*}: p<0.05 ;{ }^{* *}: p<0.01$. 


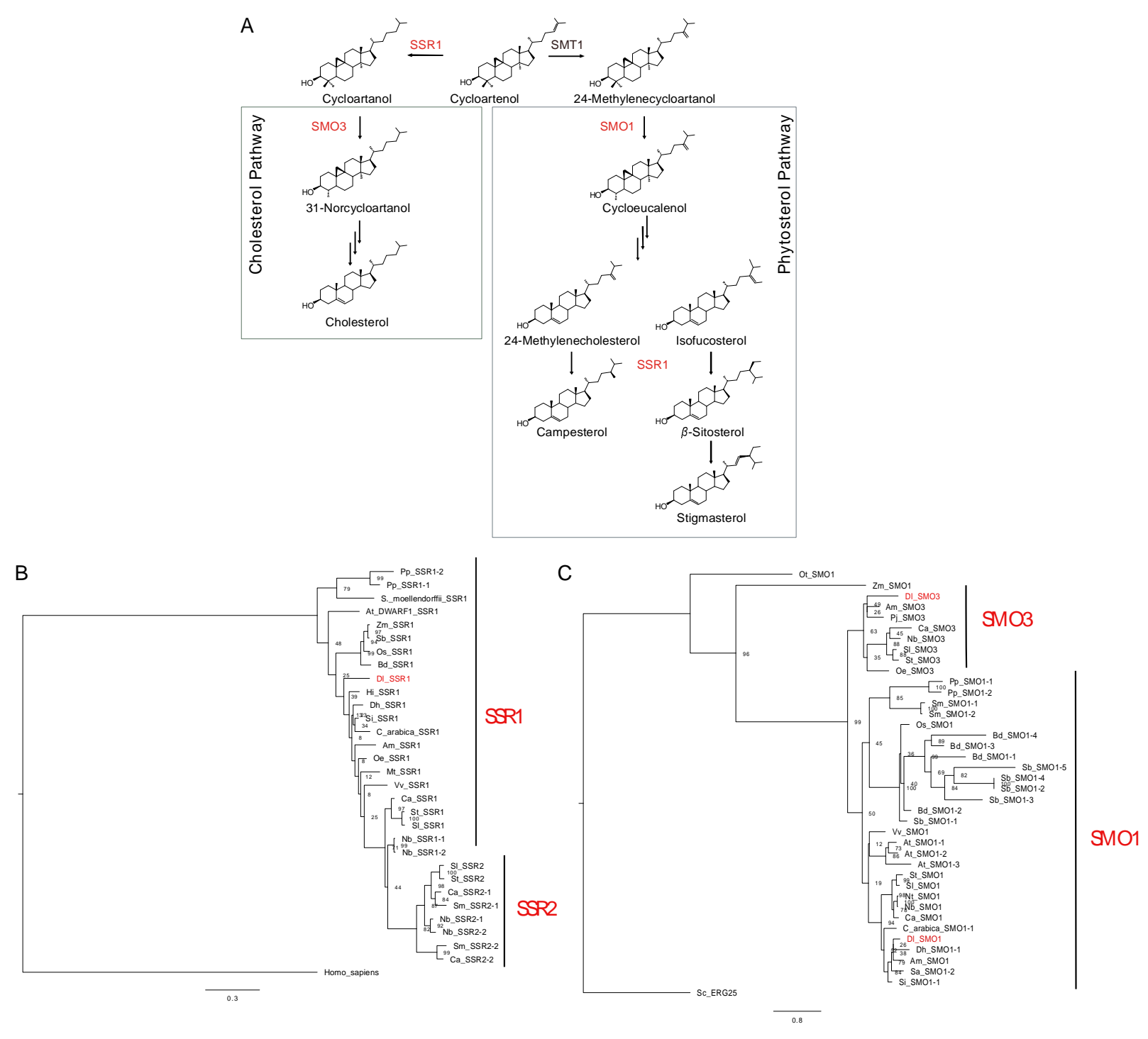

Figure 7. Duplication of the rate-limiting C4 sterol methyl oxidase (SMO1) in sterol biosynthetic pathways of Digitalis lanata. A. Proposed cholesterol and phytosterol biosynthetic pathways in $D$. lanata. Enzymes analyzed in this study are in red. B and C. Phylogenetic relationships among SMO and SSR proteins of D. lanata (DI), Antirrhinum majus (Am), Sesamum indicum (Si), Handroanthus impetiginosus (Hi), Dorcoceras hygrometricum (Dh), Olea europaea (Oe), Striga asiatica (Sa), Coffea arabica, Solanum lycopersicum (SI), Solanum tuberosum (St), Nicotiana tabacum (Nt), Nicotiana benthamiana $(\mathrm{Nb})$, Capsicum annuum $(\mathrm{Ca})$, Solanum melongena (Sm), Oryza sativa (Os), Medicago truncatula (Mt), Zea Mays (Zm), Arabidopsis thaliana (At), Physcomitrella patens (Pp), Phtheirospermum japonicum (Pj), Sorghum bicolor (Sb), Vitis vinifera (Vv), Brachypodium distachyon (Bd), Selaginella moellendorffii, Ostreococcus tauri, Ostreococcus lucimarinus, Chlamydomonas reinhardtii, Volvax carteri, Homo sapiens, and Saccharomyces cerevisiae. Maximum likelihood trees are rooted in Homo sapiens and $S$. cerevisiae. Boot-strap values (1000 replicates) are indicated at the nodes. Values above 70 are considered as high-confidence groupings. The scale bar at the bottom represents the mean number of amino acid substitutions per site on the branch of the tree. 


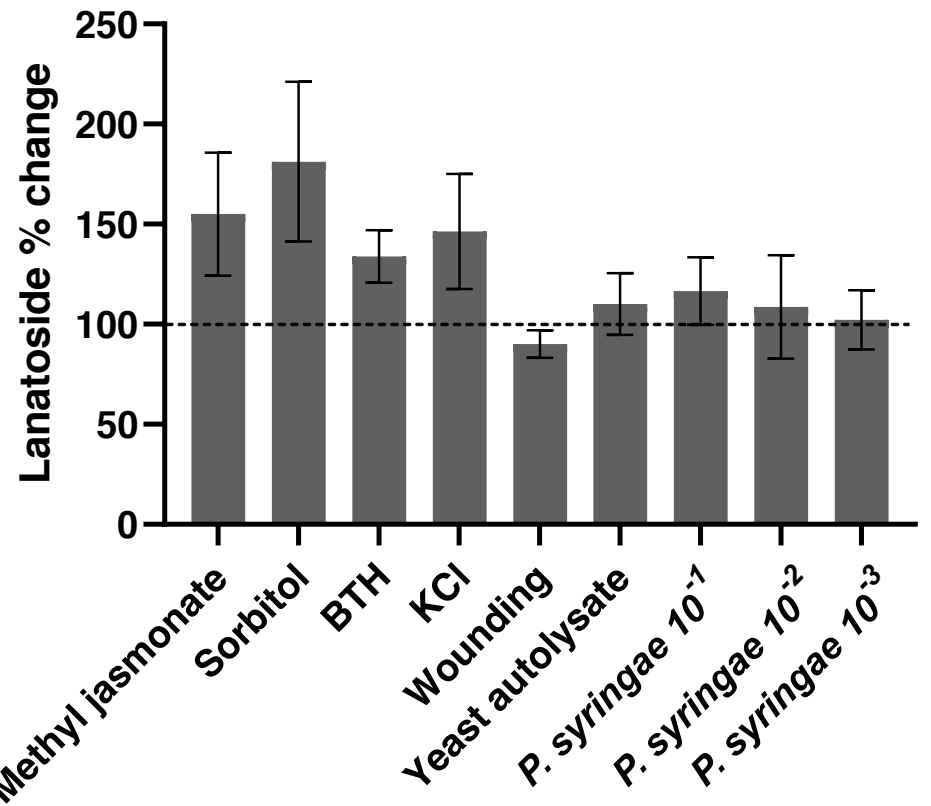


A

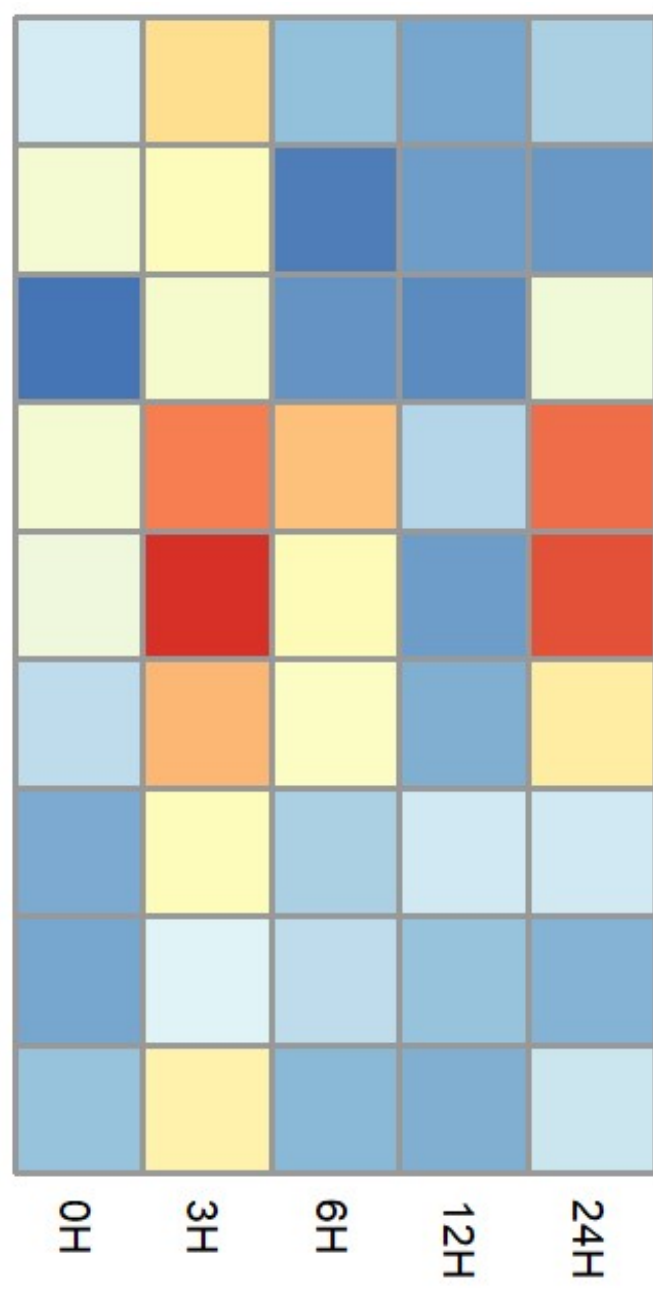

after $\mathrm{MJ}$ treatment
Glucoverodoxin

Glucodigifucoside

Odorobioside G

Glucolanadoxin

Lanatoside B

Lanatoside $\mathrm{E}$

Lanatoside A

a/b-Acetyldigitoxin

Total cardenolides

50
B

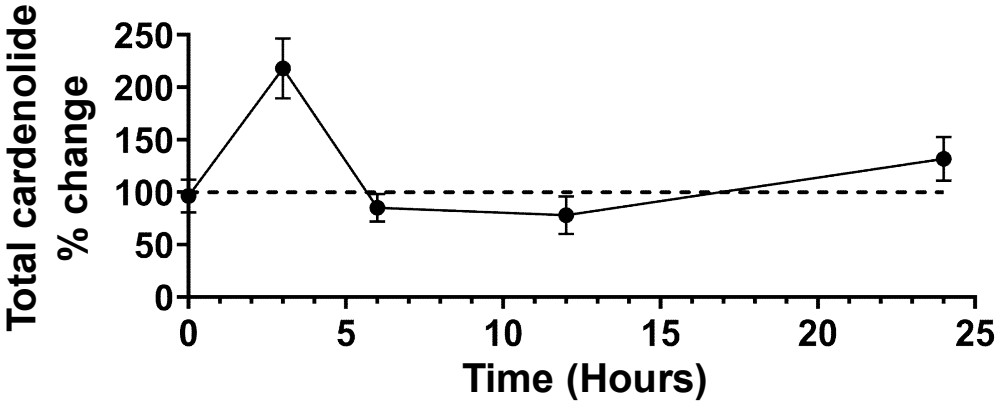

250

200

150

100

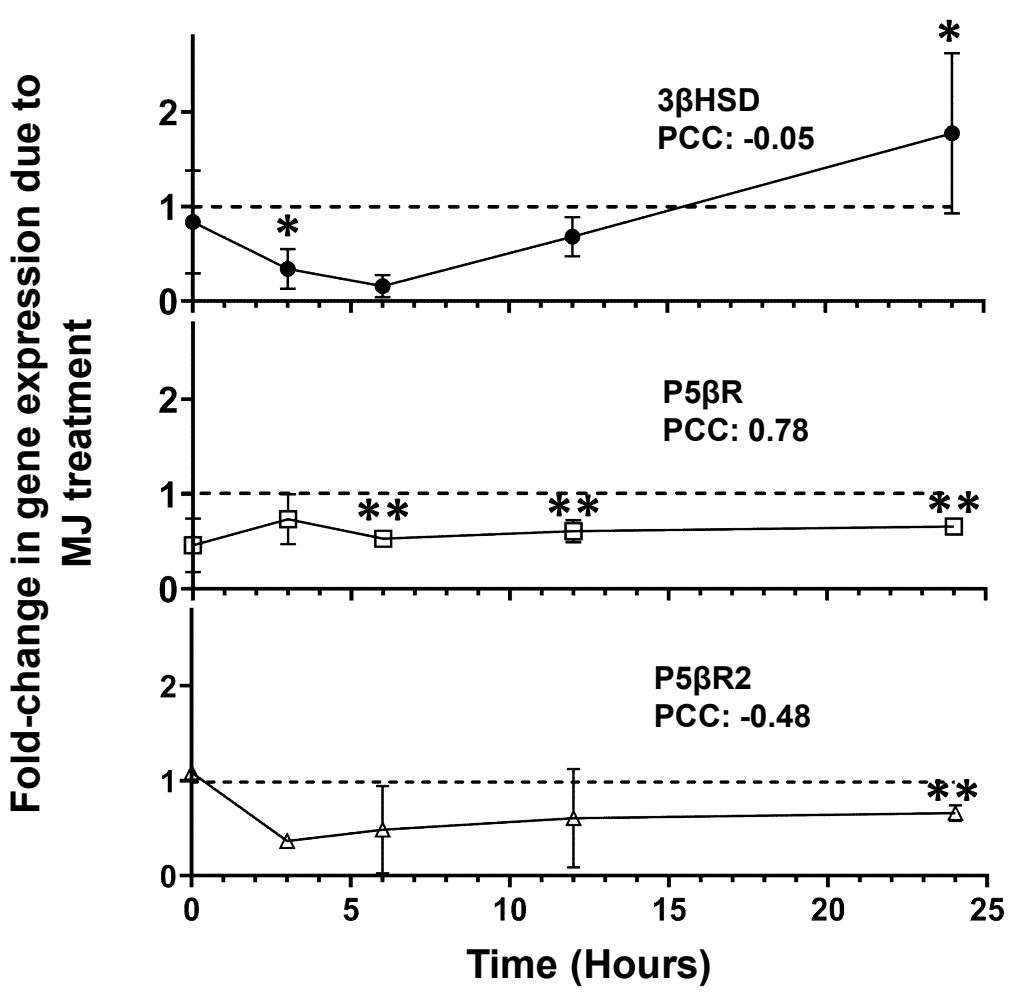


A

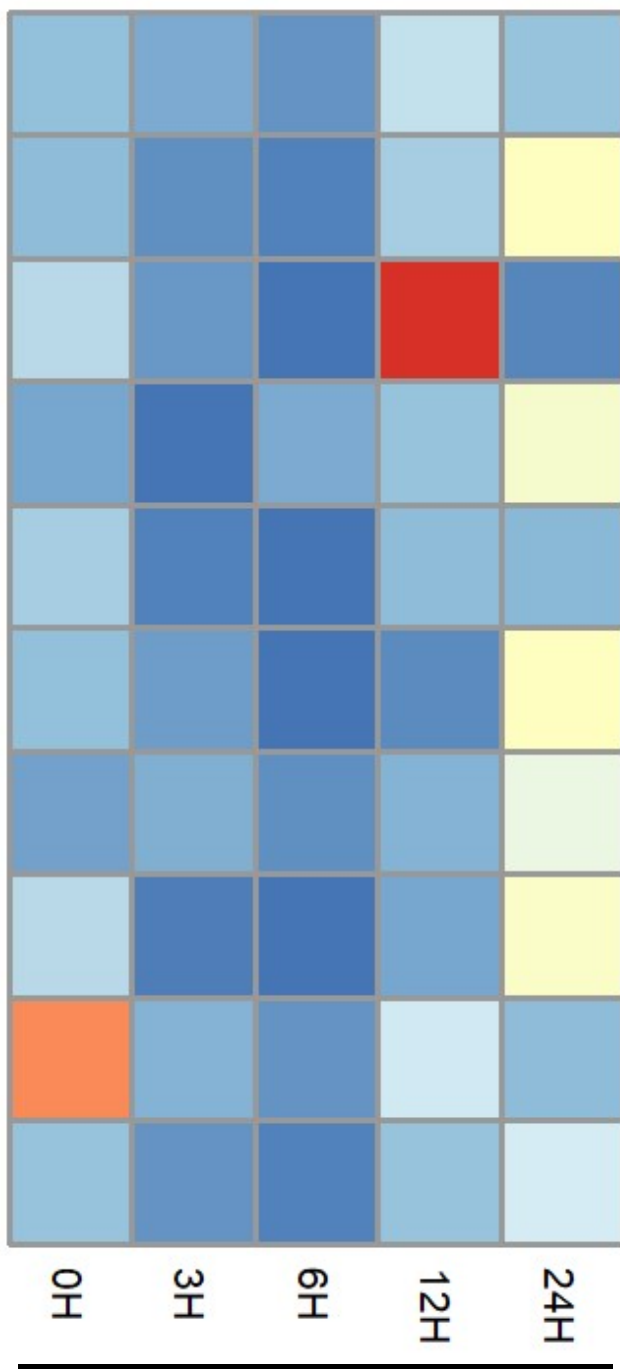

after sorbitol treatment
B

Glucoverodoxin

400

Glucodigifucoside

Odorobioside G

Glucolanadoxin

Lanatoside C

Lanatoside B

Lanatoside $\mathrm{E}$

Lanatoside A

a/b-Acetyldigitoxin

Total cardenolides

\section{0}

300

C

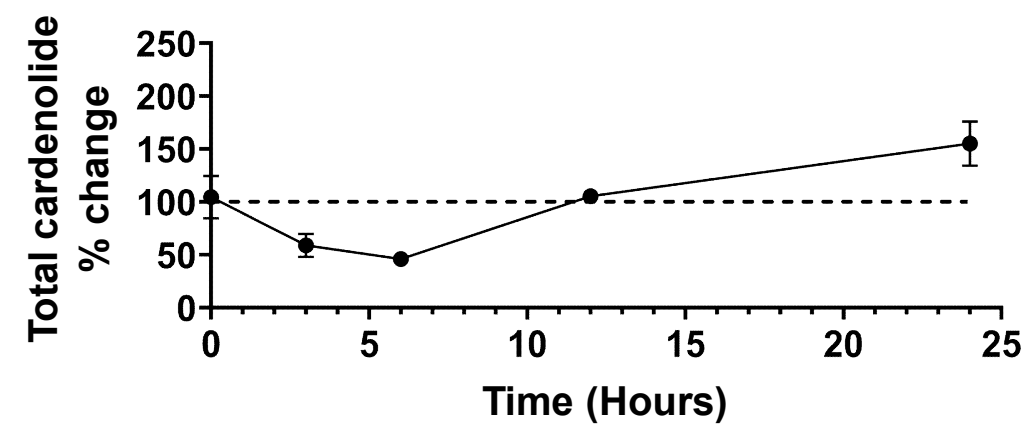

100

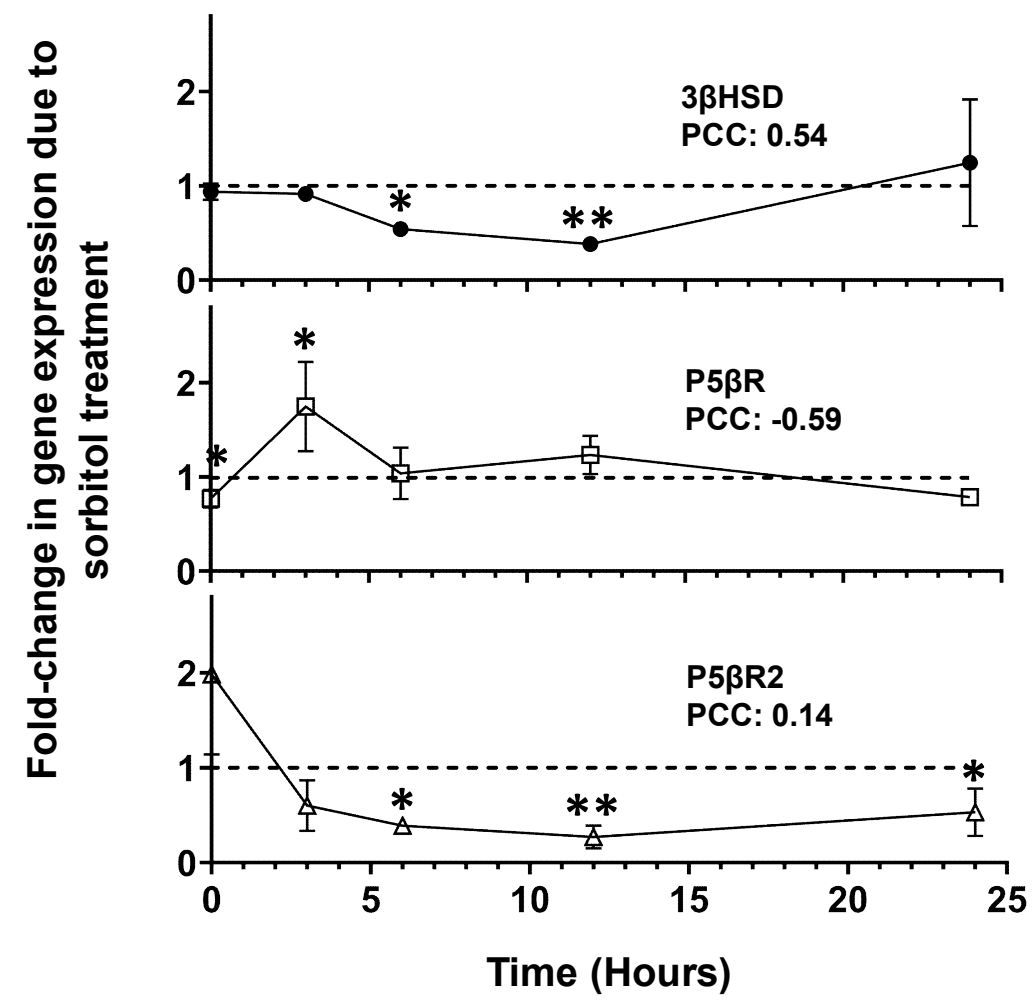


A

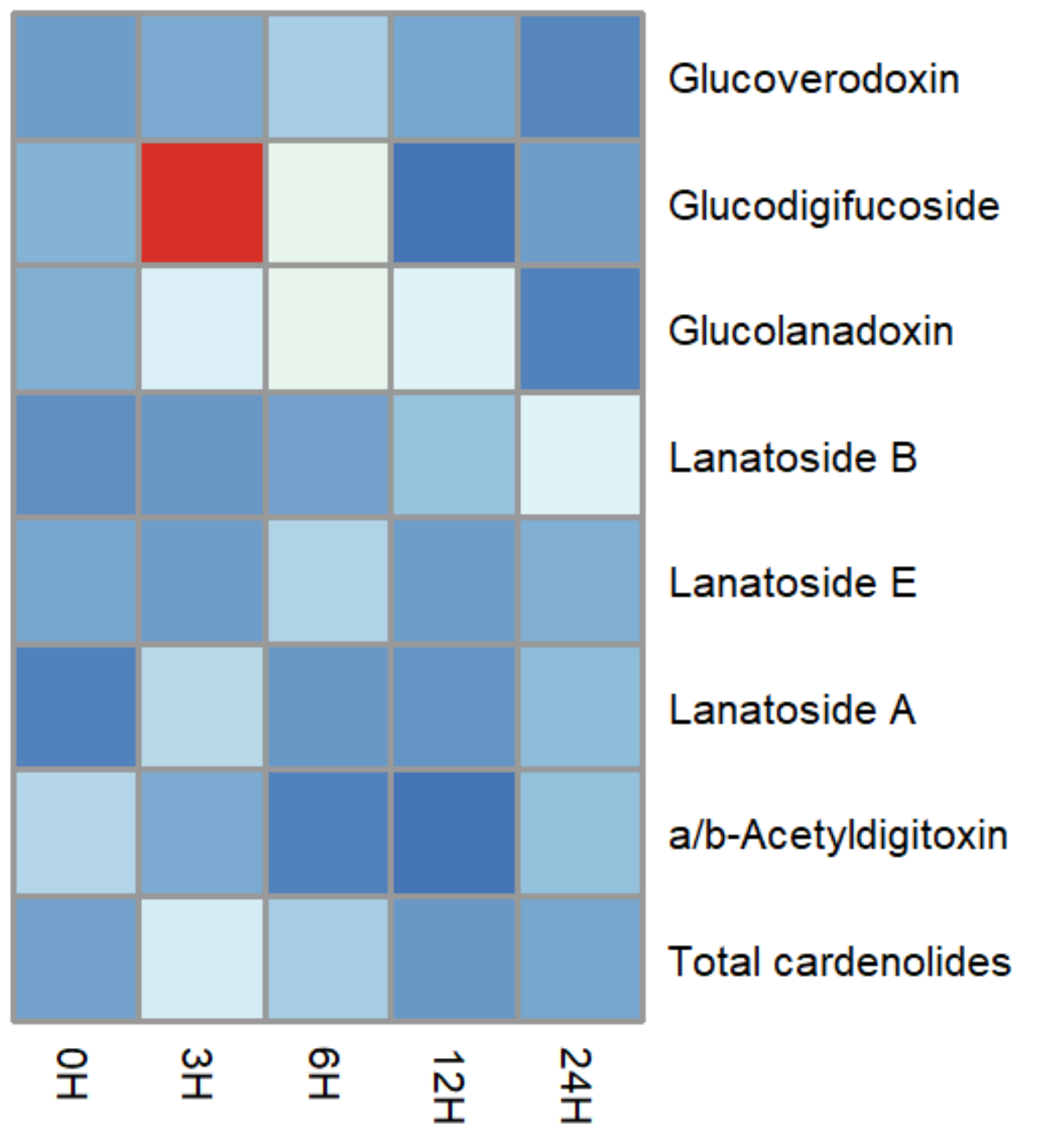

B

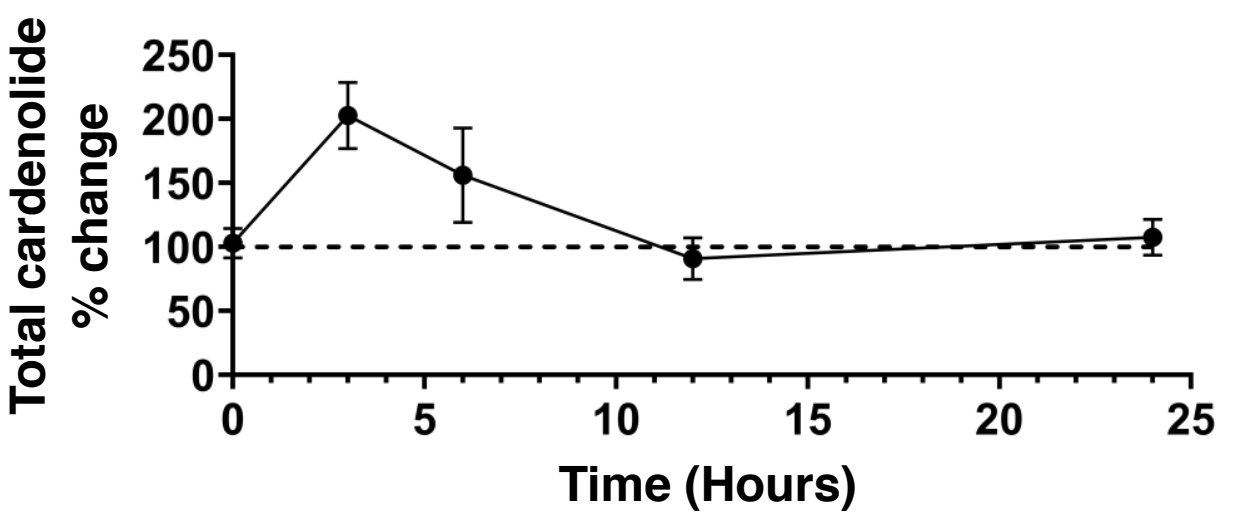

400

C

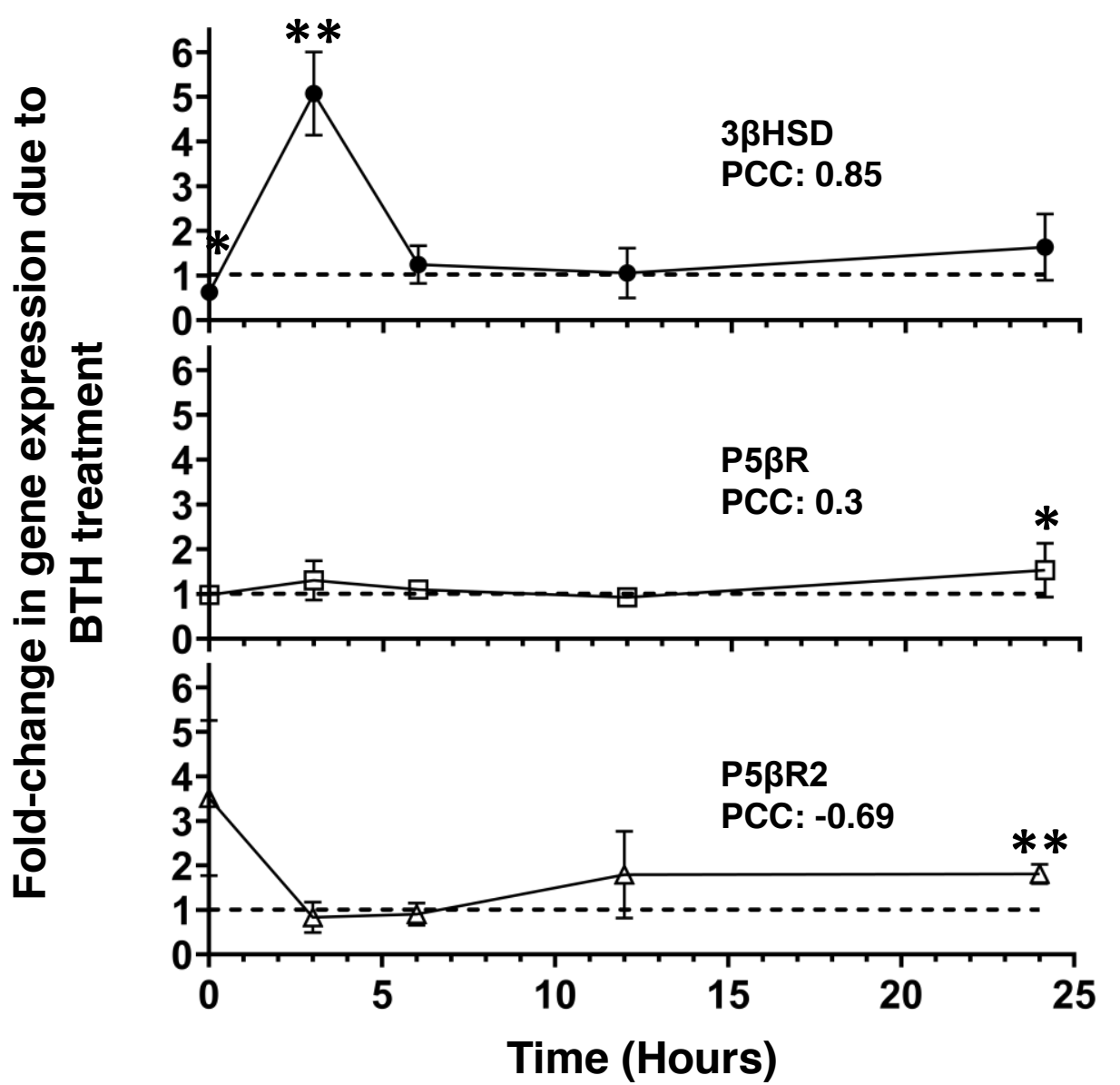


A

B
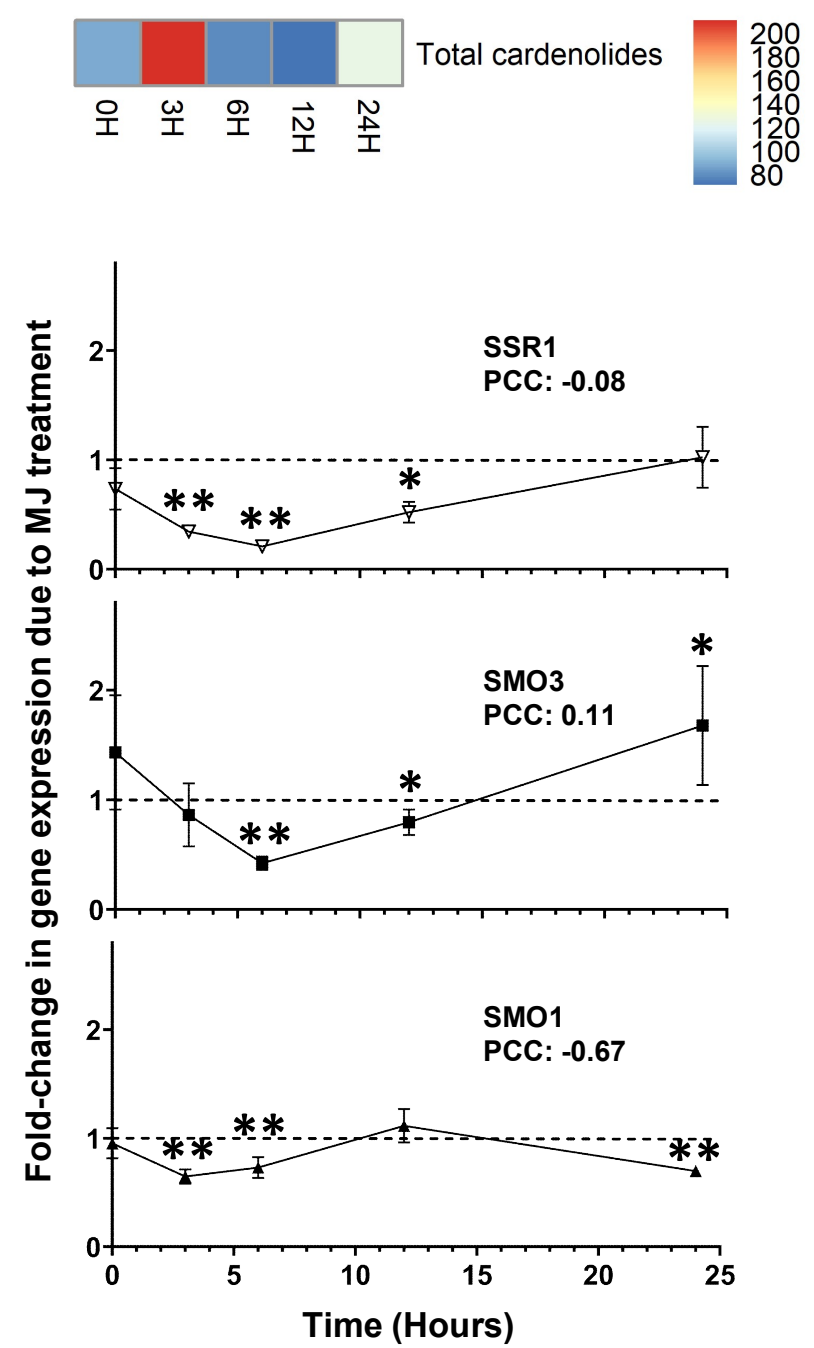

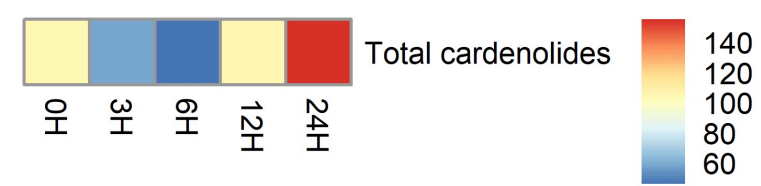

C
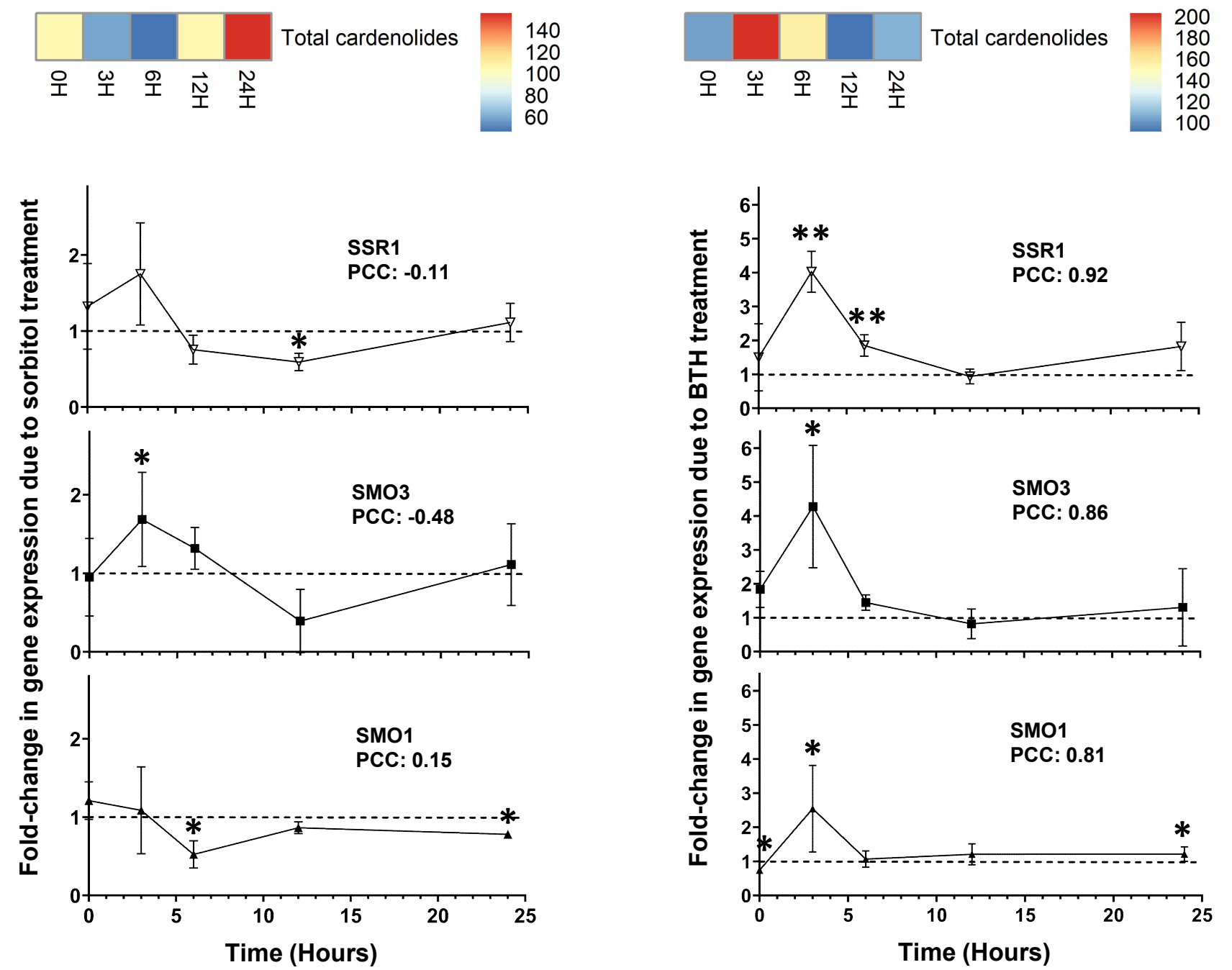
bioRxiv preprint doi: https://doi.org/10.1101/2021.09.27.461964; this version posted September 27, 2021. The copyright holder for this preprint (which was not certified by peeffeview) is the author/funder, who has granted bioRxiv a license to display the preprint in perpetuity. It is made available und्đRáCC-BY-NG-NDSM!O International license.

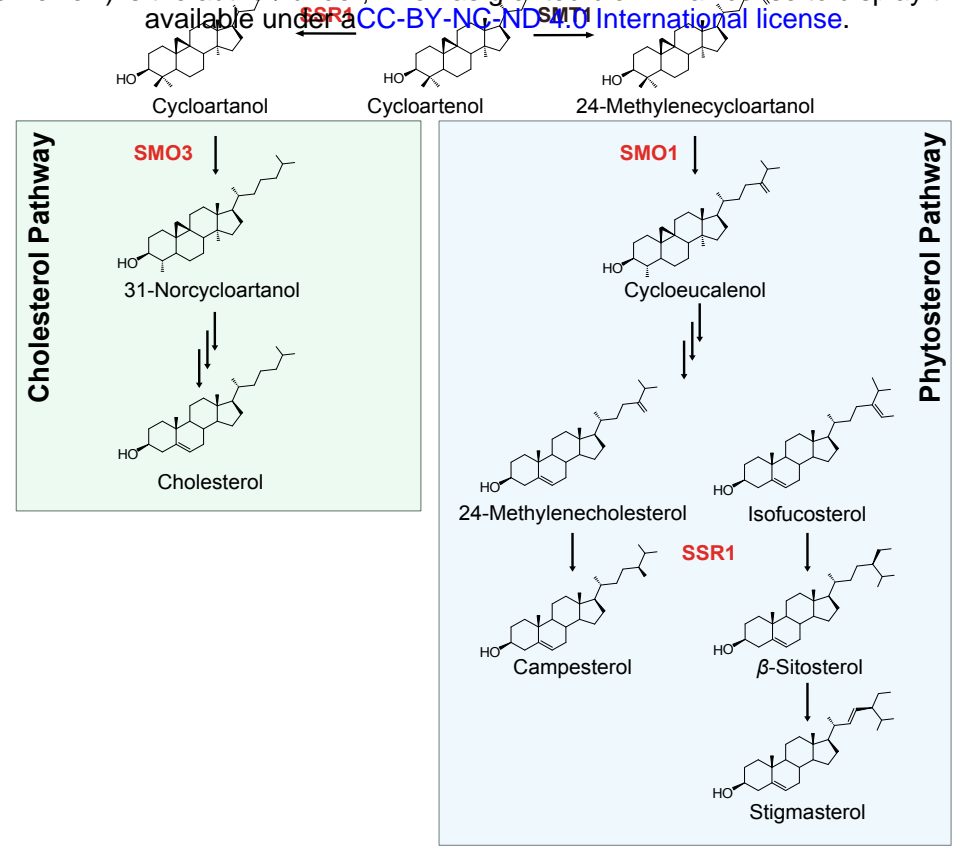

B

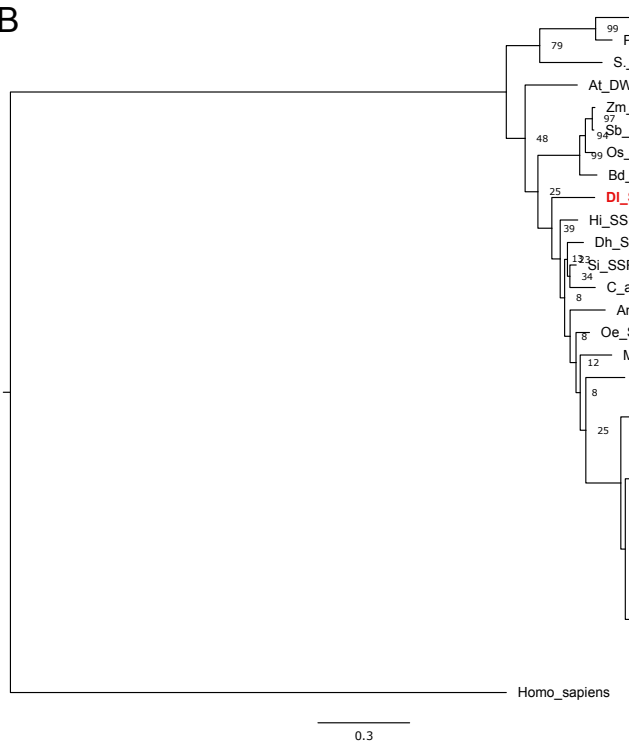

C

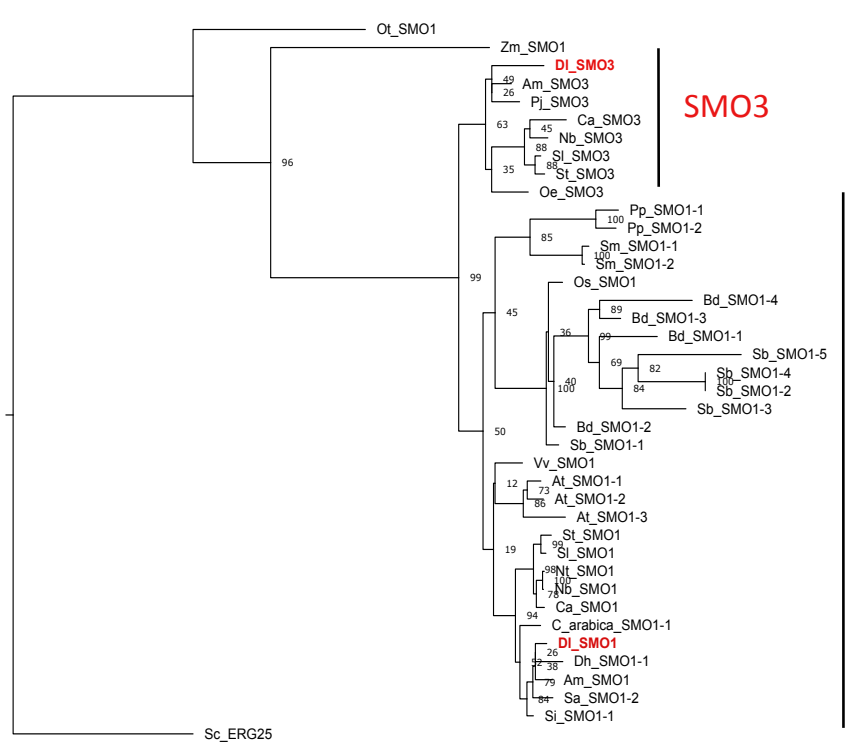

